\title{
Shared vision and autonomous motivation vs. financial incentives driving success in corporate acquisitions
}

\author{
Byron C. Clayton* \\ Case Western Reserve University, Cleveland, OH, USA
}

\section{Edited by:}

Scott N. Taylor, Babson College, USA

\section{Reviewed by:}

James Gaskin, Brigham Young University, USA

Margaret M. Hopkins, University of Toledo, USA

*Correspondence:

Byron C. Clayton, Case Western

Reserve University, 1684

McCausland Drive, Hudson,

Cleveland, OH 44236, USA

e-mail: bclayton@nortech.org

\begin{abstract}
Successful corporate acquisitions require its managers to achieve substantial performance improvements in order to sufficiently cover acquisition premiums, the expected return of debt and equity investors, and the additional resources needed to capture synergies and accelerate growth. Acquirers understand that achieving the performance improvements necessary to cover these costs and create value for investors will most likely require a significant effort from mergers and acquisitions (M\&A) management teams. This understanding drives the common and longstanding practice of offering hefty performance incentive packages to key managers, assuming that financial incentives will induce in-role and extra-role behaviors that drive organizational change and growth. The present study debunks the assumptions of this common M\&A practice, providing quantitative evidence that shared vision and autonomous motivation are far more effective drivers of managerial performance than financial incentives.
\end{abstract}

Keywords: shared vision, mergers and acquisitions, self-determination theory, autonomous motivation, financial incentives, extra-role behaviors, M\&A

\section{INTRODUCTION}

The poor financial returns and high failure rates of mergers and acquisitions (M\&A) have been thoroughly documented. Researchers have indicated that approximately $70-80 \%$ of mergers and acquisitions do not create significant value above the annual cost of capital (Bruner, 2002). Even conservative estimates place M\&A failure rates at approximately $50 \%$ or higher for nearly four decades (Kitching, 1974; Rostand, 1994; Coffey et al., 2003). Despite this conspicuously disappointing history, global M\&A activity continues to increase at a phenomenal rate climbing from $\$ 1.9$ trillion in 2004 (Cartwright and Schoenberg, 2006) to a record-breaking $\$ 4.35$ trillion in 2007 (Reuters, 2008). With trillions of dollars in transactions at risk each year, it is extremely important for researchers and practitioners to find ways to curb M\&A failures.

In order to succeed, M\&As must create value for its investors despite new costs such as servicing debt, funding growth, and increasing return expectations to accommodate acquisition premiums $^{1}$ (Sirower, 2000). These burdens require M\&A managers to increase the performance of their firms to new heights. Acquirers typically offer substantial financial incentives to induce these managers to go above and beyond their normal job duties to champion aggressive organizational change and growth (Hitt et al., 2001).

This expectation is in direct conflict with social psychology theories such as Self-Determination Theory (SDT) (Gagne and Deci, 2005) and economic theories such as Motivation Crowding

\footnotetext{
${ }^{1}$ Acquisition premium: The actual cost of acquiring a target versus its book value, market value, or estimated value. Sirower (2000) estimates that the average acquisition premium is in excess of $40 \%$.
}

Theory (Frey and Jegen, 2001; James, 2005) which assert that financial incentives can reduce motivation and performance. Certainly, the persistently high M\&A failure rates suggest the possibility that these theories apply to M\&A managers.

The purpose of the present study is two-fold. First, it explores the effects of financial incentives on the motivation and performance of M\&A managers. For completeness, our concept of managerial performance includes both in-role and championing behaviors. Second, the study explores two other practices that are used by acquirers to increase the performance of its acquired managers, increasing organizational support and focusing on shared vision.

\section{THE NEED FOR INNOVATIVE APPROACHES TO M\&A RESEARCH}

Fifty years of M\&A research have had no measurable impact on failure rates (Cartwright, 2005). Scholars continue to be bewildered by the conflicting and seemingly unpredictable performance of mergers and acquisitions (Tichy, 2001; King et al., 2004; Stahl and Voigt, 2004). M\&A research has primarily focused on three streams of inquiry to identify the root cause(s) of failures: strategic fit, culture fit and integration process (Cartwright and Schoenberg, 2006). While these research paths have contributed much to our understanding of organizational-level changes related to M\&A, neither has provided a consistent explanation of how and why these changes affect firm performance (King et al., 2004; Cartwright, 2005).

Scholars have offered several suppositions why existing M\&A literature has not been effective. First, although psychological theorists consistently argue that human factors are the key to M\&A success or failure (Cartwright and Cooper, 1996; Terry, 2003), 95\% of existing M\&A literature focuses on organizationallevel constructs (Cartwright, 2005). This is rather surprising 
since organizational change, particularly the accelerated change experienced by most M\&As, is usually if not always mediated through individual change (Schein, 1980; Schneider et al., 1996; Edmonson, 1999; Devos et al., 2001). M\&A literature fails to predict the performance of merged or acquired companies simply because it cannot predict the performance of the managers charged with running these companies (Cartwright, 2005).

Two other suppositions suggest that most M\&A studies (a) have not been theory-driven or (b) have been limited to case studies, both of which lack the generalizability to offer far-reaching solutions (Hogan and Overmeyer-Day, 1994; Seo and Hill, 2005). As a result, countless organizational practices have been prescribed for M\&A planning and integration without a sound theoretical or empirical basis, certainly contributing to the high rate of failures (Seo and Hill, 2005). In fact, researchers concluded that "changes to both M\&A theory and research may be needed" after analyzing the inability of 93 studies to clearly identify antecedents that consistently impact M\&A performance (King et al., 2004). Evidently, unique approaches to M\&A research is just as important as the research focus.

\section{CONCEPTUAL OVERVIEW}

In a ground-breaking analysis of M\&A failures, Sirower (2000) illustrated how most M\&A management teams face massive required performance improvements (RPIs) to achieve M\&A success. The basic M\&A premise involves purchasing a company at $X$ price, then growing its value to $X+Y$ at some designated time in the future. The value of Y must be sufficiently large enough to cover the acquisition premium, the expected return of debt and equity investors, surges in competitive activity responding to the M\&A threat, additional resources requirements needed for growth and capturing synergies, acquisition transaction and consulting costs, executive contractual costs, and many other costs including the time value of money (Sirower, 2000). For M\&A managers, status quo performance of in-role behaviors, no matter how efficient, will no longer suffice. Management performance must often substantially improve to meet the RPIs dictated by the need to achieve value $Y$. As such, M\&A managers are expected to champion aggressive organizational change and growth to have any chance of achieving M\&A success.

Understanding this dynamic, acquirers typically focus on three areas to improve in-role behaviors and more importantly, to induce championing behaviors from acquired managers: financial incentives, organizational support and shared vision. The most common and longstanding practice is to increase financial performance incentives via some combination of stock options, profit sharing, gain sharing or individual bonuses. In fact, acquirers often establish financial incentives as part of the transaction terms for key managers and immediately after the transaction for other managers (Hitt et al., 2001; Cullinan et al., 2004). Acquirers understand that any delays in achieving performance improvements quickly compound the returns needed to accommodate value $Y$. Sirower (2000) calculated that expectations of a $10 \%$ return on equity (ROE) would increase to approximately $15 \%$ on minimal or substandard returns for the first couple of years after an acquisition. This 50\% increase in ROE would have to be maintained for the following 7 years just to break even. In other words, his analysis assumes no value creation, only value preservation for the acquirer. Consequently, acquirers typically provide substantial performance incentives expecting they will induce key managers to champion whatever changes are necessary to achieve the acquirer's goals. This practice is supported by empirical studies on compensation, which in general, report a positive influence of monetary incentives on employee and firm performance (Booth and Frank, 1999; Lazear Edward, 2000; Gerhart and Rynes, 2003; Gagne and Forest, 2008).

Unfortunately, the exceptionally high rates of M\&A failures indicate that increasing performance incentives do not consistently increase the performance of acquired managers. This directly contradicts common practice and general compensation literature. However, economics and social psychology scholars have provided theory and corresponding empirical evidence describing certain conditions where financial incentives are ineffective and in fact, can actually undermine motivation and performance (Gagne and Deci, 2005; James, 2005). This suggests the presence of a mediator that suppresses the total effect of financial incentives on performance.

This mediation effect is supported by SDT (Gagne and Deci, 2005). SDT posits that individuals perceive financial incentives as control mechanisms. As such, financial incentives reduce individuals' autonomous motivation, that is, their willingness to act on organizational goals according to their own volition.

Figure 1 graphically depicts the aforementioned assertions regarding the direct and mediation effects of financial incentives on in-role and championing behaviors in a single model. The model illustrates the positive relationship between incentives and performance behaviors espoused by general compensation literature and M\&A practice. It also illustrates the negative mediation effect of autonomous motivation espoused by SDT.

Providing organizational support is another common method acquirers use to improve in-role performance and induce championing behaviors. When parent organizations actively demonstrate a concern for acquired employees' well-being, threat is reduced, motivating employees to willingly reciprocate with actions that contribute to the well-being of the organization (Gaertner et al., 2001; Seo and Hill, 2005). Two of the most successful and studied serial acquirers, Cisco Systems and GE Capital, both consider their organizational support of acquired employees during post-acquisition integration as the key to their success (DiGeorgio, 2001). Figure 1 depicts organizational support as positively impacting both autonomous motivation and managerial performance.

Shared vision is the third common method used by M\&A practitioners to maximize performance (Douma et al., 2000; Mitleton-Kelly, 2004; Stahl and Mendenhall, 2005). We define shared vision as a manager's focus and alignment toward the new regime's direction and purpose. M\&A literature asserts that a shared vision is essential to the successful performance of merged and acquired organizations (Haspeslagh and Jemison, 1991; Sitkin and Pablo, 2005). J. P. Garnier, the former CEO of GlaxoSmithKline, extensively discussed the importance of management's focus on shared vision when analyzing GSK's many 


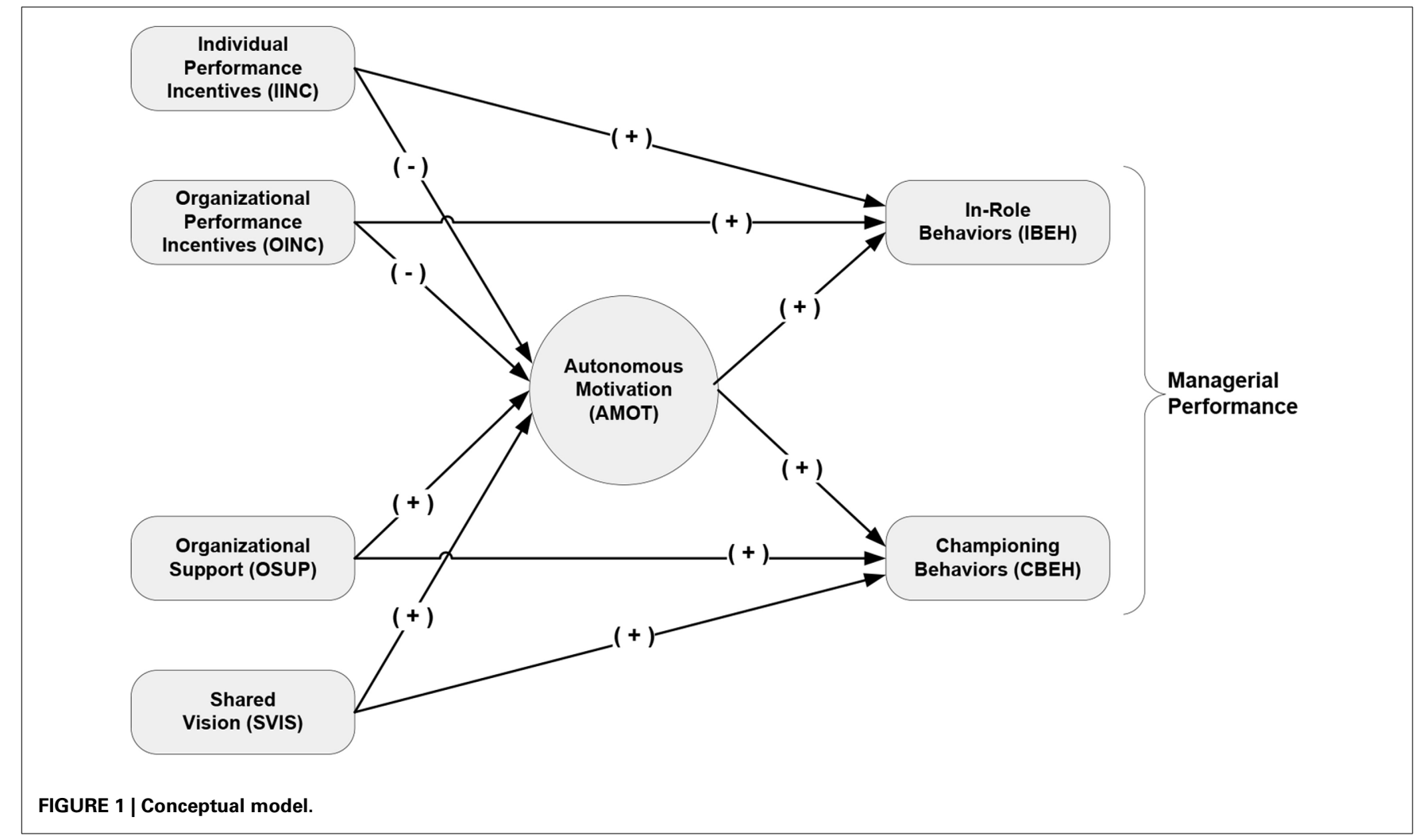

M\&A successes (Stahl and Mendenhall, 2005). Cisco System explores shared vision as part of the pre-acquisition process while GE Capital requires its integration managers to develop shared vision during the post-acquisition integration process as part of their role (DiGeorgio, 2001). Per Figure 1, we posit that shared vision positively influences both autonomous motivation and championing behaviors.

\section{MANAGERIAL PERFORMANCE}

Our definition of managerial performance consists of in-role behaviors and championing behaviors. In-role behaviors are defined and required by formal job descriptions (Williams and Anderson, 1991; Riketta, 2002). They are recognized and driven by an organization's formal reward system (Barksdale and Werner, 2001). Researchers most often characterize in-role behaviors as simply "doing one's job."

Championing behaviors are a form of extra-role behaviors based on the "taking charge" construct defined by Morrison and Phelps (1999). Like other forms of extra-role behaviors, they are discretionary actions that are not defined or enforced by formal role obligations (Morrison and Phelps, 1999). Unlike other forms of extra-role behaviors, they are specifically change-oriented, describing individuals who are willing to challenge the status quo to bring about constructive organizational change (Morrison and Phelps, 1999). Championing behaviors describe voluntary efforts to continuously improve organizational functioning. Researchers have statistically confirmed their relation to but distinction from other forms of extra-role behaviors (Morrison and Phelps, 1999; Chiaburu and Baker, 2006).

\section{THE DIRECT EFFECTS OF FINANCIAL INCENTIVES ON IN-ROLE PERFORMANCE}

Performance incentives for acquired managers can take several forms. Table 1 lists the most common incentives categorized by their basis of evaluation. Researchers over the past decade have consistently reported that at least $95 \%$ of U.S. companies provide performance incentives with approximately $35 \%$ of those companies providing individual-based incentives and $60 \%$ providing organizational-based incentives (Bucklin and Dickinson, 2001; McGee et al., 2006). Because increasing performance is so essential to the success of mergers and acquisitions (Sirower, 2000), we suspect that an even higher percentage of M\&As provide some form of performance incentives.

This common practice of using performance incentives is based on research on compensation showing financial incentives have a positive effect on employee performance (Gerhart and Rynes, 2003) with studies showing a 4-9\% increase in firm performance (Booth and Frank, 1999; Lazear Edward, 2000; Gagne and Forest, 2008). Because financial strategists dominate M\&A literature and practice (Sudarsanam, 2003; Cartwright, 2005), it is not surprising that they have adopted the perspective supported by the financial literature regarding compensation. M\&A literature specifically recommends performance incentives that range from "cash compensation for particular actions to stock options and equity ownership" (Hitt et al., 2001), to drive "stimulating sustained, vigorous performance" (Larsson and Finkelstein, 2002), because "incentives matter a great deal in determining the success of an acquisition (Kaplan, 2000). 
Table 1 | Common performance incentives for managers.

\begin{tabular}{|c|c|c|c|}
\hline Evaluation basis & Performance incentive & Description & Major pros and cons \\
\hline $\begin{array}{l}\text { Individual } \\
\text { performance }\end{array}$ & $\begin{array}{l}\text { Individual performance } \\
\text { bonus }\end{array}$ & $\begin{array}{l}\text { Cash compensation based on achieving individual } \\
\text { goals. Funded by pre-determined budget set } \\
\text { aside for bonuses }\end{array}$ & $\begin{array}{l}\text { Pros: Excellent influence on individual } \\
\text { performance. Cons: Promotes self-interest and } \\
\text { competition among peers }\end{array}$ \\
\hline $\begin{array}{l}\text { Organizational } \\
\text { performance }\end{array}$ & Profit sharing bonus & $\begin{array}{l}\text { Cash or deferred compensation based on the } \\
\text { economic performance of the firm. Funded by } \\
\text { firm profits }\end{array}$ & $\begin{array}{l}\text { Pros: Signals willingness to share wealth with } \\
\text { workforce. Easy to administer. Cons: Weak } \\
\text { influence on day to day individual performance }\end{array}$ \\
\hline $\begin{array}{l}\text { Organizational } \\
\text { performance }\end{array}$ & Gainsharing bonus & $\begin{array}{l}\text { Cash compensation based on specific short or } \\
\text { long-term operational goals. Funded by cost } \\
\text { savings, increased revenue or productivity gains }\end{array}$ & $\begin{array}{l}\text { Pros: Good to excellent influence on individual } \\
\text { performance depending on the size of the group. } \\
\text { Promotes cooperation, team work and positive } \\
\text { peer pressure. Cons: Can be difficult to } \\
\text { administer and keep current }\end{array}$ \\
\hline $\begin{array}{l}\text { Organizational } \\
\text { performance }\end{array}$ & Stock or stock options & $\begin{array}{l}\text { Stock or the right to purchase stock at a fixed } \\
\text { price. Funded by the sale of the firm or of the } \\
\text { firm's stock }\end{array}$ & $\begin{array}{l}\text { Pros: Easy to administer. Can be a substantial } \\
\text { amount. Cons: Weak influence on day to day } \\
\text { individual performance }\end{array}$ \\
\hline
\end{tabular}

From a theoretical perspective, the direct effect of incentives on performance is based on the economic exchange model (Blau, 1964) that promises specific benefits from the organization in return for specific contributions from employees (Tsui et al., 1997). Equity Theory, one of many theories that utilize the economic exchange model, asserts that employees strive to balance the contributions they provide relative to the benefits they receive (Adams, 1965; Cropanzano et al., 2007). According to Equity Theory, financial incentives should positively influence the performance of an individual's specified behaviors, that is, in-role behaviors. Accordingly, studies have supported a positive correlation between performance incentives and in-role behaviors (Deckop et al., 1999), specifically referring to it as the pay-performance link (Bucklin and Dickinson, 2001).

\section{Hypothesis 1: Individual performance incentives positively influence in-role behaviors after controlling for autonomous motivation.}

Hypothesis 2: Organizational performance incentives positively influence in-role behaviors after controlling for autonomous motivation.

Compensation specialists have historically cited the payperformance link to be the most important factor in determining the influence that financial incentives have on an individual's performance (Bucklin and Dickinson, 2001). The strength of the pay-performance link depends on the amount of control an individual has over achieving the targeted goals (McGee et al., 2006). The more control one has over achieving the goals, the more control he has over his pay.

One has much more control over achieving individual-based goals than group-based goals (McGee et al., 2006). Simply put, the less people involved in achieving a goal, the more that a single participant can control the outcome. In addition, organizational performance incentives are based on the impact of operational or economic outcomes on the firm, many of which depend on external variables that are clearly beyond the control of management (Bucklin and Dickinson, 2001) such as the economy, government regulation, customer demand, and competitor strategies. Even controllable variables such as productivity and quality are an aggregate based on the performance of all employees, meaning that an individual may perceive his contribution as insignificant toward achieving the incentive (FitzRoy and Kraft, 1995; Hall and Murphy, 2003). As a result, individuals may have difficulty seeing the connection between group-based incentives and their day-today performance of in-role behaviors (Bucklin and Dickinson, 2001; Hall and Murphy, 2003).

Hypothesis 3: Individual performance incentives have a stronger (more positive) influence on in-role behaviors than organizational performance incentives.

\section{THE MEDIATING EFFECTS OF AUTONOMOUS MOTIVATION ON FINANCIAL INCENTIVES}

Mediating effects on financial incentives are not considered by the economic exchange based theories that dominate compensation research and practice (Frey and Osterloh, 2005; Gagne and Forest, 2008). However, numerous studies have explored how certain conditions can cause tangible incentives to undermine motivation and performance (Gagne and Deci, 2005; James, 2005). This "hidden cost of reward" was first identified and researched by social psychologists as far back as 1971 (Titmuss, 1971; Lepper and Greene, 1978; Frey and Oberholzer-Gee, 1997). Over the years, this concept has been included in many theoretical approaches to work motivation and performance such as Cognitive Evaluation Theory (Deci and Ryan, 1985) and Motivation Crowding Theory (Frey and Jegen, 2001; James, 2005).

SDT posits that the perceptions of tangible incentives regulate an individual's motivation and behaviors (Deci and Ryan, 2000; Ryan and Deci, 2000a; Sheldon et al., 2003; Gagne and Deci, 2005). Referring to Figure 2, the Self-Determination Continuum, the source of regulation describes the reasons that individuals act on the organizational goals. When an individual generally regards organizational goals as personally important, meaningful or interesting, they are internalized or internally valued by the 


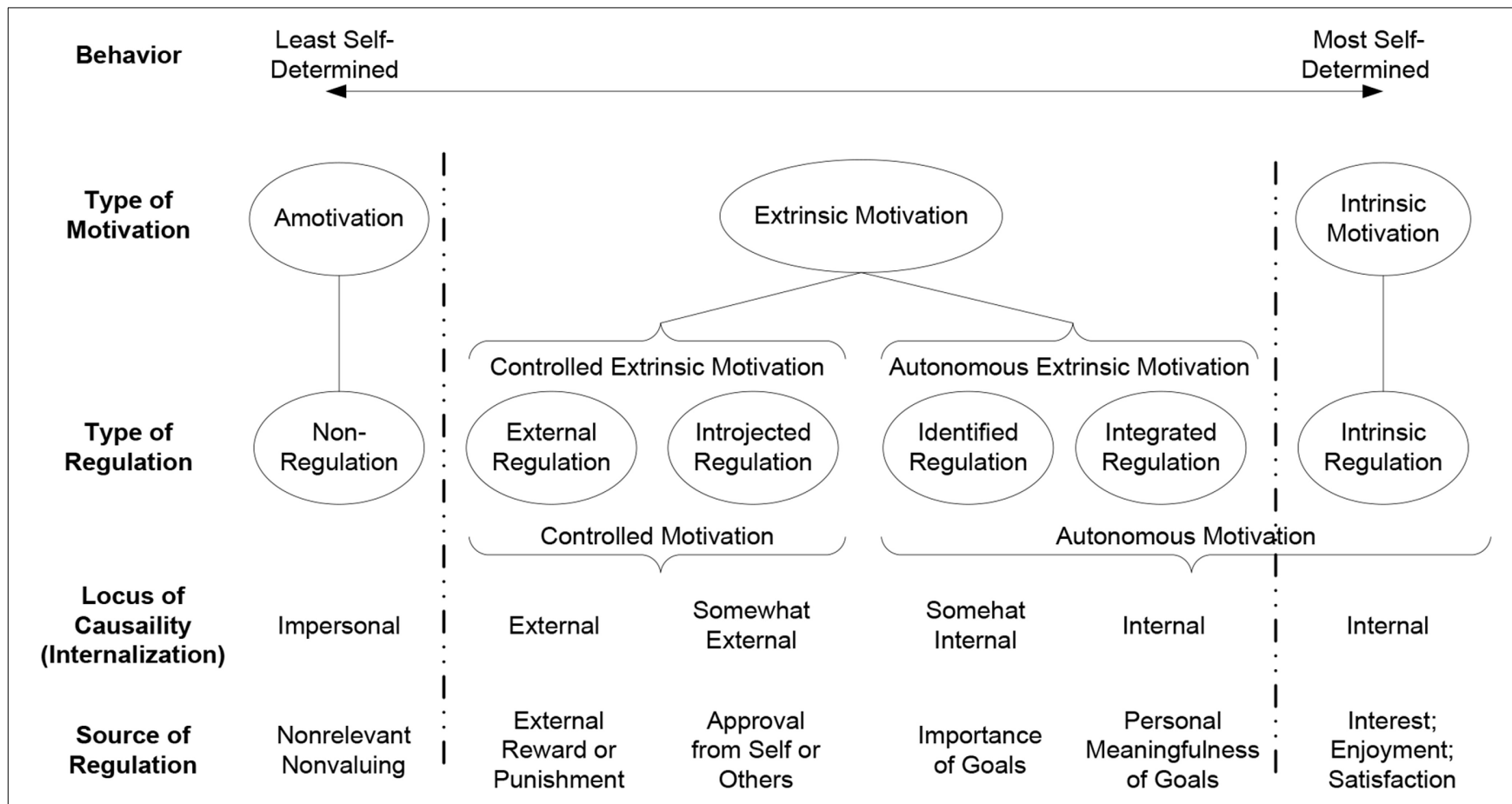

Adapted from several sources: Deci \& Ryan 2000; Ryan \& Deci 2000a; Gagne \& Deci 2005; Sheldon et al 2003

FIGURE 2 | Self-determination continuum.

individual (Ryan and Connell, 1989; Sheldon et al., 2003; Gagne and Forest, 2008). High degrees of internalization enhance an individual's perceived autonomy, resulting in their willing intention to act on organizational goals (Deci and Ryan, 1987; Gagne and Deci, 2005). SDT defines this willing intention to act as autonomous motivation. Conversely, an individual that generally regards organizational goals with low degrees of internalization will only act on them to receive a reward, avoid a punishment or achieve the approval of others (Ryan and Deci, 2000a; Meyer et al., 2004). SDT refers to this as controlled motivation.

Figure 2 depicts the sources of regulation that include external rewards increase controlled motivation while reducing autonomous motivation. SDT states that individuals perceive tangible rewards as control mechanisms, attempting to force or coerce them into acting on organizational goals. SDT posits that tangible rewards reduce autonomous motivation.

Hypothesis 4: Individual performance incentives negatively influence autonomous motivation.

Hypothesis 5: Organizational performance incentives negatively influence autonomous motivation.

Researchers have proposed that organizational commitment is actually a component of work motivation (Meyer and Herscovitch, 2001; Meyer et al., 2004). Empirical research has confirmed considerable overlap between both major conceptualizations of organizational commitment (O'Reilly and Chatman, 1986; Meyer and Allen, 1991) and the SDT framework of work motivation (Gagne and Deci, 2005; Gagné et al., 2009). Affective organizational commitment, characterized as the willing desire to identify with an organization was specifically linked to autonomous motivation (Gagné and Koestner, 2002; Gagné et al., 2004; Gagne and Deci, 2005).

A number of studies have linked affective organizational commitment to in-role and extra-role behaviors. Researchers have established a significant overlap between affective organizational commitment and autonomous motivation. In a meta-analysis of 93 published studies, affective organizational commitment was found to (a) positively influence in-role behaviors, (b) to positively influence extra-role behaviors, and (c) to influence extra-role behaviors significantly more than in-role behaviors (Riketta, 2002). Similar results were also reported in a separate meta-analysis of 155 independent samples involving more than 50,000 employees (Meyer et al., 2002).

Hypothesis 6: Autonomous motivation positively influences in-role behaviors.

Hypothesis 7: Autonomous motivation positively influences championing behaviors.

Hypothesis 8: Autonomous motivation has a stronger (more positive) influence on championing behaviors than in-role behaviors.

Hypotheses 1 through 8 establish autonomous motivation as a mediator of the influence that performance incentives have on in-role and championing behaviors. Because SDT posits a negative relationship between financial incentives and 
autonomous motivation, our hypothesized model conceptualizes that autonomous motivation negatively mediates the impact of incentives on managerial performance. This is in accordance with SDT but directly conflicts with M\&A practice.

Hypothesis 9: Autonomous motivation negatively mediates the influence of individual performance incentives on in-role behaviors.

Hypothesis 10: Autonomous motivation negatively mediates the influence of organizational performance incentives on in-role behaviors.

Hypothesis 11: Autonomous motivation negatively mediates the influence of individual performance incentives on championing behaviors.

Hypothesis 12: Autonomous motivation negatively mediates the influence of organizational performance incentives on championing behaviors.

\section{THE EFFECTS OF ORGANIZATIONAL SUPPORT ON MANAGERIAL PERFORMANCE}

The present study conceptualizes organizational support through the perceptions of each individual manager. Perceived organizational support (POS) captures an individual's beliefs concerning the degree to which an organization values their contributions and cares about their well-being (Eisenberger et al., 1986). POS develops from an employee's personification of the organization and its intent toward favorable or unfavorable treatment and working conditions (Rhoades and Eisenberger, 2002). High levels of POS indicate a work environment that is likely to exhibit fair treatment, participation in decision-making, career development and training, job security, recognition, supervisor support and a strong sense of belonging (Wayne et al., 1997; Rhoades and Eisenberger, 2002; Masterson and Stamper, 2003).

Social Exchange Theory (SET), a foundation for understanding the relationships between individuals and their organizations, posits that an individual is likely to reciprocate the favorable or unfavorable treatment received from an organization (Blau, 1964). On the basis of SET, POS should drive an individual's willing desire to act on behalf of the organization (Rhoades and Eisenberger, 2002). In a meta-analysis of over 70 studies on the antecedents and outcomes of POS, Rhoades and Eisenberger (2002) identified a strong and consistent positive relationship between POS and affective commitment. Given the established relationship between affective organizational commitment and autonomous motivation, we propose the following:

Hypothesis 13: Organizational support positively influences autonomous motivation.

Rhoades and Eisenberger's meta-analysis (2002) also reports that extra-role behaviors toward the organization as a significant outcome of POS. A recent study corroborates those findings, specifically confirming that POS is the antecedent to extra-role behaviors (Chen et al., 2009).

Hypothesis 14: Organizational support positively influences championing behaviors.
Hypotheses 6, 7, 13, and 14 establish autonomous motivation as a mediator of the influence that organizational support has on in-role and championing behaviors. The positive effects conceptualized for each hypothesis posits that autonomous motivation positively mediates the impact of organizational support on managerial performance.

Hypothesis 15: Autonomous motivation positively mediates the influence of organizational support on in-role behaviors.

Hypothesis 16: Autonomous motivation positively mediates the influence of organizational support on championing behaviors.

\section{THE EFFECTS OF SHARED VISION ON MANAGERIAL PERFORMANCE}

M\&A literature asserts that a shared vision, defined as a common direction and purpose among an M\&A's leaders and employees, is essential to its successful performance (Haspeslagh and Jemison, 1991; Sitkin and Pablo, 2005). A shared vision of an organization's future must be consistently encouraged and communicated to take root, spread and foster an environment of excellence (Senge, 1990). An effective shared vision provides the focus, direction and purpose for day-to-day individual efforts. They remind us of the meaning and importance of our work (Boyatzis and McKee, 2005).

Shared vision is particularly important in M\&A environments because it is a bonding mechanism that helps different parts of an organization combine resources which promotes the integration of the entire organization (Tsai and Ghoshal, 1998). At an individual level, shared vision creates an emotional bond between an employee and his organization, providing a common identity and sense of belonging (Senge, 1990; Dvir et al., 2004). This sense of belonging enhances relatedness, which according to SDT, increases autonomous motivation In other words, an individual who agrees with or is inspired by the organization's vision is more likely to willingly act on behalf of the organization (Ashforth and Humphrey, 1995; Dvir et al., 2004).

Hypothesis 17: Shared vision positively influences autonomous motivation.

Intentional Change Theory posits that shared vision drives the types of behaviors that cultivate and sustain individual, group and organizational change (Akrivou et al., 2006; Boyatzis, 2006; Van-Oosten, 2006). We contend that these behaviors are closely related, if not identical to championing behaviors. Championing behaviors consist of discretionary conduct focused on implementing constructive organizational change (Morrison and Phelps, 1999; Chiaburu and Baker, 2006).

\section{Hypothesis 18: Shared vision positively influences championing} behaviors.

Hypotheses 6, 7, 17, and 18 establish autonomous motivation as a mediator of the influence that shared vision has on in-role and championing behaviors. The positive effects conceptualized for each hypothesis posit that autonomous motivation positively mediates the impact of shared vision on managerial performance. 
Hypothesis 19: Autonomous motivation positively mediates the influence of shared vision on in-role behaviors.

Hypothesis 20: Autonomous motivation positively mediates the influence of shared vision on championing behaviors.

\section{RESEARCH METHODS}

\section{SAMPLE}

The study focuses on mergers and acquisitions owned by private equity firms. Private equity firms typically have a 5-7 year turnaround timetable for their investments (Flanigan, 2005). To this end, managers must implement aggressive, short-term growth strategies designed to quickly improve the firm's performance to levels never before achieved. The study targets firms that were acquired at least 3 months prior to the survey. M\&As less than 3 months old have not had sufficient time for changes in financial incentives to have an effect on the attitudes and behaviors of acquired managers. Three months is a common milestone used by M\&A practitioners to judge the direction of early-stage change implementation (DiGeorgio, 2001; Bertoncelj and Kovač, 2007).

Companies owned by private equity provide an excellent climate to evaluate the drivers of managerial performance. Private equity ownership fosters an environment of time-constrained, aggressive-growth expectations that require high levels of in-role and championing behaviors from M\&A managers.

The sample consists of CEOs, senior managers and middle managers from $54 \mathrm{M} \&$ As owned by a large private equity firm headquartered in North America The M\&As are middle market companies with revenues ranging from \$5-500 million annually that compete in a variety of industries. The study defines senior managers as those who report directly to the CEO or president and middle managers as one or two reporting levels below senior managers. The sample provides a comprehensive representation of managers that receive individual and organizational based performance incentives. CEOs and senior manages usually participate in incentive plans based on stock performance, receiving stock or stock options. Middle managers usually participate in incentive plans based on organizational performance such as gainsharing or profit sharing. Both senior and middle managers commonly receive incentives based on individual performance in addition to stock or organizational incentives. Table 2 provides a description of the respondents who completed surveys.

\section{DATA COLLECTION}

The researchers developed an online survey designed to collect self-report data regarding performance incentives, motivation, shared vision and organizational support. A secondary survey and procedure were designed to collect performance data from each respondent's immediate supervisor. Unfortunately, the sponsoring organization did not approve the secondary survey for distribution to its managers. Therefore, the researchers expanded the primary survey to include self-reported performance. IRB exemption was obtained but all protocols governing use of human subjectgs were followed. Out of 500 managers solicited, 306 returned completed surveys for a $61 \%$ response rate.

\section{Measures}

Each of the measures used to develop the survey were based on existing validated scales using 5 point Likert responses with the exception of the performance incentive measures and controls. The performance incentive items simply reported the level of financial inducements as a percentage of base salary. The controls were reported management level or demographic information.

\section{Performance incentives}

Individual performance incentives are financial bonuses based solely on the performance of the manager in relation to formal job duties. Organizational performance incentives are financial rewards based on the performance of the organization. Organizational incentives include profit sharing bonuses, gainsharing bonuses and stock options. Being a report of factual data, these items followed the standard practice of measuring financial incentives as percentages or multiples of base salary (Murphy et al., 1999).

\section{Autonomous motivation}

The items chosen to measure autonomous motivation were adapted from the Relative Autonomy Index (RAI) originally developed by Ryan and Connell (1989) and its subsequent adaptations (Williams and Deci, 1996; Black and Deci, 2000). The Relative Autonomy Index measured each type of motivation described by SDT according to its degree of autonomy (Millette and Gagné, 2008). The RAI is computed by subtracting the scores from its controlled motivation subscale from its autonomous motivation subscale, such that the more positive scores indicate higher levels of autonomous motivation (Deci and Ryan, 2008). However, according to Deci and Ryan (2008), analyses can also be conducted using either of the two subscales. Three items for each subscale were selected for this study-the item numbers correspond to the item number in the original scales.

\section{Organizational support}

The researchers chose five items from the nine-item version of the POS scale (Eisenberger et al., 1990; Wayne et al., 1997) to operationalize organizational support. The POS scale describes employee perceptions about the extent an organization values

Table 2 | Description of respondents.

\begin{tabular}{|c|c|c|c|c|c|c|c|c|c|c|c|c|c|c|}
\hline \multicolumn{3}{|c|}{ Management level (MLVL) } & \multicolumn{3}{|c|}{ Acquisition age (AAGE) } & \multicolumn{3}{|c|}{ Age (PAGE) } & \multicolumn{3}{|c|}{ Tenure (PTEN) } & \multicolumn{3}{|c|}{ Gender (PGEN } \\
\hline CEOs & 23 & $8 \%$ & 90 days -3 years & 120 & $39 \%$ & $18-29$ & 68 & $22 \%$ & $<3$ years & 98 & $32 \%$ & Male & 254 & $83 \%$ \\
\hline Senior managers & 90 & $29 \%$ & $3+$ year & 186 & $61 \%$ & $30-44$ & 154 & $50 \%$ & $3-10$ years & 96 & $31 \%$ & Female & 52 & $17 \%$ \\
\hline Middle managers & 191 & $62 \%$ & & & & $45+$ & 84 & $27 \%$ & $10+$ years & 112 & $37 \%$ & & & \\
\hline
\end{tabular}

Non-managers $2 \quad 1 \%$ 
their contributions and cares about their well-being. The items were selected because of their more consistent Cronbach's alpha coefficients of $0.81-0.93$ as compared to the original (36-item) and revised (17-item) versions with reliabilities ranging from.074 to.095 (Wayne et al., 1997; Moorman et al., 1998; Fields, 2002). The five items selected for this study have the item numbers corresponding to the item number in the original scale.

\section{Shared vision}

Five items were selected from the vision subscale of the PNEA Survey (Boyatzis, 2008) to measure shared vision. The PNEA vision subscale measures the respondent's focus on and alignment with the organization's vision. The five items were chosen (from eight items in the referenced subscale) because of their particular relevance to the context of the present study. The five items selected for this study have the item numbers corresponding to the item number in the original scale.

\section{In-role behaviors}

Managerial in-role behaviors were assessed using five items adapted from a multi-dimensional scale designed to measure employee performance in the workplace (Williams and Anderson, 1991; Turnley et al., 2003). The in-role behaviors subscale specifically measures behaviors recognized by the formal reward system (Williams and Anderson, 1991; Turnley et al., 2003). This measure has been extensively used for peer, supervisor and selfreports (Fields, 2002).

\section{Championing behaviors}

Championing behaviors were measured by the "taking charge" scale which was developed to assess an individual's discretionary actions toward organizational change (Morrison and Phelps, 1999). These types of extra-role behaviors challenge the status quo by implementing changes or correcting problems in an effort to constructively improve organizational functioning. Championing behaviors are distinctively different from the altruistic, conscientious or civic virtue behaviors measured by most extra-role or organizational citizenship instruments and therefore, require a specific assessment tool (Morrison and Phelps, 1999; Chiaburu and Baker, 2006). The researchers chose the taking charge scale to operationalize championing behaviors because it targets the aggressive, change-oriented behaviors most M\&As require from their managers to succeed. Five items were adapted to weigh the respondent's efforts toward solving pressing organizational problems or implementing new systems, technologies or methodologies, all of which are essential for accelerating M\&A growth and performance.

\section{Control variables}

The influence of incentives, organizational support and shared vision may also vary with managerial hierarchy. Higher-level managers are likely to have different informational and interpersonal relationships with parent organizations, which could result in different attitudes (Tsui et al., 1997). A multigroup analysis was conducted to evaluate structural model invariance across senior managers and middle managers. The process involves comparing the goodness of fit between a model with structural paths constrained equal across groups to a model with no constraints (Byrne, 2001). A significant difference in chi-square indicates the models are not invariant, warranting each constraint to be released, one at a time, to pinpoint the specific paths causing the variance.

Multigroup analysis was also used to assess model invariance of managers under 45 years old to those 45 and older. Part of the M\&A due diligence effort, when considering an acquisition, is to evaluate the management team. While some acquirers prefer younger management teams, feeling they are more flexible and dynamic, other acquirers prefer older management teams, feeling they are more experienced and knowledgeable (Wiersema and Bantel, 1992). The multigroup analyses was undertaken to identify if performance incentives, organizational support and shared vision affected the behaviors of senior and middle managers differently.

Other factors may impact M\&A managers as well. Gender and company tenure are often considered as human capital factors that influence workplace performance (Tsui et al., 1997). As such, we included these items as control variables.

\section{METHOD OF ANALYSIS}

Normality, homoscedasticity and multicollinearity were examined; extreme outliers and influentials removed, and linear relationships were confirmed. An exploratory factor analysis (EFA) followed to uncover the latent structure of the measurement model in relation to a priori assumptions. The resulting measurement model was then subjected to a confirmatory factor analysis (CFA) to assess its fit to the data using structural equation modeling (SEM) methodologies. The researchers used SPSS and AMOS statistical software packages to conduct data and measurement model analyses.

Common method variance was of particular concern in the present study because the survey instrument was administered at the same time, in the same context, to single respondents, all of which can contribute to inflating the relationships between constructs (Podsakoff et al., 2003; Friedrich et al., 2009). Podsakoff et al. (2003) advocated the single-common-methodfactor approach to control for CMV, particularly when the predictor and criterion measures were obtained from the same source and in the same context, as in this case. The procedure calls for establishing a latent factor in the measurement model which loads on each observed item. The main advantage of this approach is that it does not require the researcher to identify and measure specific causes of CMV. Unfortunately however, this approach also reflects the variance for other unmeasured variables in addition to CMV (Podsakoff et al., 2003). Other disadvantages include the tendency for this approach to result in under-identified models, particularly when the number of items is small in relation to the number of constructs, as in this case. As a solution to this problem, some researchers constrain the CMV factor loadings to be equal (Podsakoff et al., 2003). We referenced this approach to control for CMV during the analyses of measurement and structural models.

Prior to analyzing the hypothesized structural model, convergent and discriminant validity of the constructs as well as their internal reliability were assessed and confirmed. SEM techniques 
were then used to evaluate the causal relationships between the constructs in the structural model (Fornell and Larcker, 1981; Byrne, 2001). Goodness of fit statistics included measures comparing predicted vs. observed covariances (chi-square, relative chi-square, and SRMR), default vs. independence models (CFI, NFI, and TLI), and predicted vs. observed covariances penalized for lack of parsimony (RMSEA). To summarize the causal relationships between constructs, the $r^{2}$ statistics for each mediating and dependent variable were tabulated with the unstandardized regression coefficient and $t$-value for each of its contributing explanatory variables.

Mediation testing followed the approach advocated by Mathieu and Taylor (2006). This approach incorporates iterative, systematic techniques designed to test for partial mediation, full mediation and indirect effects models. Its primary focus is on identifying indirect effects, specifically those that may suppress the total effects between predictor and criterion variables, causing many researchers to overlook important mediating relationships. The a priori assumptions of suppression effects in our hypothesized model warranted the use of this approach.

Finally, we examined the effects of the designated controls on our results. Management level and participant age were of particular interest. Therefore, multigroup analysis procedures were used to test the invariance of our model across senior and middle managers, as well as managers under and over 45 years old. Both measurement and structural models were tested for invariance.

\section{RESULTS}

SEM requires sample sizes greater than 200 with five to ten cases per observed variable (Kline, 2005; Hair et al., 2006). The original dataset consisted of 306 cases and 28 observed variables, meeting the data adequacy requirements for SEM. Subsequent analyses resulted in a final dataset of 285 cases and 20 observed variables, still exceeding the minimum requirements for SEM.

The pre-screening process identified two cases of respondents who were not CEOs, senior managers or middle managers. The cases were removed from the dataset. SPSS generated box plots, stem and leaf diagrams, and histograms as well as skewness and kurtosis values were examined to confirm acceptable normality of the observed variables. The analysis resulted in the identification and removal of 11 outliers from the dataset.

Each dependent variable was regressed on all independent variables which confirmed linear relationships suitable for SEM analysis. For each regression, SPSS generated plots of the standardized residuals against the standardized predicted value to confirm homoscedasticity of the variables. Finally, the regressions also produced collinearity statistics, confirming that all tolerance and VIF statistics were below the acceptable multicollinearity thresholds of $<0.10$ and $>10$, respectively (Kline, 2005).

An EFA was conducted using Principal Axis Factoring and Promax rotation to uncover the minimum number of factors required to account for the maximum amount of common variance assuming oblique relationships, not orthogonal. Twentyeight observed variables were loaded into SPSS for EFA analysis. The items measuring individual and organizational performance incentives were not included in EFA. These measures assessed the amount and type of incentives reported by the respondents. As
Table 3 | Simultaneous EFA of observed variables with rotated factor loadings ( $n-285$, EFA conducted with principal axis factoring and promax rotation and kaisaer normalization).

\begin{tabular}{|c|c|c|c|c|c|}
\hline Variables & Factor 1 & Factor 2 & Factor 3 & Factor 4 & Factor 5 \\
\hline \multicolumn{6}{|c|}{ AUTONOMOUS MOTIVATION (AMOT) } \\
\hline AREG1 & & & & & 0.620 \\
\hline AREG3 & & & & & 0.896 \\
\hline AREG 6 & & & & & 0.833 \\
\hline \multicolumn{6}{|c|}{ ORGANIZATIONAL SUPPORT (OSUP) } \\
\hline OSUP1 & & & & 0.588 & \\
\hline OSUP4r & & & & 0.898 & \\
\hline OSUP5 & & & & 0.950 & \\
\hline \multicolumn{6}{|c|}{ SHARED VISION (SVIS) } \\
\hline SVIS1 & & 0.952 & & & \\
\hline SVIS2 & & 0.919 & & & \\
\hline SVIS3 & & 0.842 & & & \\
\hline \multicolumn{6}{|c|}{ IN-RLE BEHAVIORS (IBEH) } \\
\hline IBEH1 & 0.962 & & & & \\
\hline IBEH3 & 0.858 & & & & \\
\hline IBEH5 & 0.916 & & & & \\
\hline \multicolumn{6}{|c|}{ CHAMPIONING BEHAVIORS (CBEH) } \\
\hline $\mathrm{CBEH} 1$ & & & 0.522 & & \\
\hline $\mathrm{CBEH} 2$ & & & 0.505 & & \\
\hline CBEH3 & & & 0.773 & & \\
\hline $\mathrm{CBEH} 4$ & & & 1.047 & & \\
\hline
\end{tabular}

such, they were single item measures that did not indicate latent variables. The initial EFA resulted in a five factor solution with most variables loading as hypothesized. However, several of the items had cross-loadings within 0.200 , had factor loadings below 0.500 , or would improve the Cronbach's alpha of the construct if it were deleted. After several iterations, a total of 10 items were removed, resulting in a clean five factor solution as depicted in Table 3.

Referring to Table 3, the Kaiser-Meyer-Olkin (KMO) and Bartlett's test of sphericity values both exceeded the desired thresholds of greater than 0.6 and less than 0.05 , respectively. KMO predicted the data would factor well while the Bartlett's test indicated acceptable correlation between variables. Five factors with eigenvalues greater than 1.0 were extracted accounting for $72.8 \%$ of the total variance. All items loaded according to hypothesized groupings and exhibited relatively high and close within each factor. That is, with the exception of CBEH (Championing Behaviors). The large spread between the maximum and minimum loadings was cause for concern. However, the construct proved to exhibit both discriminant and convergent validity (confirmed in a following section) and so, the four items were retained.

The CMV factor loadings were statistically significant indicating that common method variance would have biased the results had we not controlled for it. All goodness of fit statistics presented in this study were calculated from models that controlled for CMV. It was not only model fit indices which accounted for CMV, but also the regression weights in the structural model. 
Table 4 | Convergent and discriminant validity statistics.

\begin{tabular}{|c|c|c|c|c|c|c|c|}
\hline Constructs/Dimensions & Coefficients $^{a}$ & $T$-value & Cronbach's Alpha & $C R^{\mathrm{b}}$ & AVE $^{c}$ & MSV $^{d}$ & ASV $^{e}$ \\
\hline Autonomous motivation (AMOT) & & & 0.80 & 0.74 & 0.50 & 0.42 & 0.25 \\
\hline AREG1 & 0.544 & 7.500 & & & & & \\
\hline AREG6 & 0.728 & 11.284 & & & & & \\
\hline Organizational support (OSUP) & & & 0.87 & 0.82 & 0.61 & 0.20 & 0.11 \\
\hline OSUP5 & 0.853 & 14.898 & & & & & \\
\hline Shared vision (SVIS) & & & 0.93 & 0.89 & 0.74 & 0.31 & 0.20 \\
\hline SVIS1 & 0.909 & 17.484 & & & & & \\
\hline SVIS2 & 0.896 & 17.217 & & & & & \\
\hline SVIS5 & 0.758 & 13.161 & & & & & \\
\hline Championing behaviors (CBEH) & & & 0.86 & 0.78 & 0.48 & 0.42 & 0.22 \\
\hline $\mathrm{CBEH} 1$ & 0.848 & 13.456 & & & & & \\
\hline $\mathrm{CBEH} 2$ & 0.785 & 12.441 & & & & & \\
\hline CBEH3 & 0.436 & 5.505 & & & & & \\
\hline $\mathrm{CBEH} 4$ & 0.638 & 9.260 & & & & & \\
\hline
\end{tabular}

a Standardized factor loadings.

${ }^{b}$ Composite Reliability.

${ }^{c}$ Average Variance Extracted.

${ }^{d}$ Maximium Shared Variance

eAverage Shared Variance.

After controlling for common method variance, the reliability and validity of each construct were assessed utilizing standardized factor loadings, composite reliabilities (CR), average variance extracted (AVE), maximum shared variance (MSV), and average shared variance (ASV) (Fornell and Larcker, 1981; Hair et al., 2006). The criteria for convergent validity includes standardized factor loadings $>0.50$, AVE $>0.50$, and $C R>0.70$. Per Table 4, all variables and constructs exceed desired thresholds except for the AVE of the Championing Behaviors construct and the standardized coefficient of one of its items, $\mathrm{CBEH} 3$. However, because the EFA inferred potential issues with different $\mathrm{CBEH}$ variables and based on the strength of other statistics, particularly Cronbach's alpha and composite reliability, no changes were made. Each construct also met the criteria for internal reliability with a Cronbach's alpha and composite reliability exceeding 0.70 (Fornell and Larcker, 1981; Nunnally and Bernstein, 1994).

AVE varies from 0 to 1 , and it represents the ratio of the total variance that is due to the latent variable. Using the logic as presented earlier, an AVE of 0.5 or more indicates satisfactory convergent validity, as it means that the latent construct accounts for $50 \%$ or more of the variance in the observed variables, on the average. If AVE is less than 0.5, the variance due to measurement error is larger than the variance captured by the construct, and the validity of the individual indicators, as well as the construct, is questionable. Note that $\mathrm{AVE}$ is a more conservative measure
Table 5 | SEM goodness of fit statistics for the structural model.

\begin{tabular}{|c|c|c|c|}
\hline Goodness of fit & $\begin{array}{l}\text { Criteria for } \\
\text { good fit }\end{array}$ & $\begin{array}{c}\text { Initial } \\
\text { structural model }\end{array}$ & $\begin{array}{c}\text { Respecified } \\
\text { structural model }\end{array}$ \\
\hline \multicolumn{4}{|c|}{ FIT OF PREDICTED VS. OBSERVED COVARIANCES } \\
\hline Chi-square (df) & $\mathrm{N} / \mathrm{A}$ & $391.7(151)$ & $363.1(148)$ \\
\hline $\begin{array}{l}\text { Relative chi-square } \\
\text { (CMIN/DF) }\end{array}$ & $<3.0^{a}$ & 2.6 & 2.1 \\
\hline SRMR & $\leq 0.08^{b}$ & 0.06 & 0.05 \\
\hline \multicolumn{4}{|c|}{ FIT OF DEFAULT VS. INDEPENDENCE MODELS } \\
\hline $\mathrm{CFI}$ & $\geq 0.95^{\mathrm{b}}$ & 0.93 & 0.94 \\
\hline $\mathrm{NFI}$ & $\geq 0.90^{c}$ & 0.90 & 0.91 \\
\hline TLI & $\geq 0.95^{b}$ & 0.91 & 0.92 \\
\hline
\end{tabular}

RMSEA $(90 \% \mathrm{Cl}) \quad \leq 0.06^{\mathrm{b}} \quad 0.075(0.066-0.084) \quad 0.072(0.062-0.081)$

a Kline (1998).

${ }^{b}$ Hu and Bentler (1999).

${ }^{c}$ Bentler and Bonett (1980).

than CR. On the basis of CR alone, the researcher may conclude that the convergent validity of the construct is adequate, even though more than $50 \%$ of the variance is due to error. One should also interpret the standardized parameter estimates to ensure that they are meaningful and in accordance with theory (Malhotra and Dash, 2011, p. 702). 
Table 6 | Statistical relationships between structural model constructs.

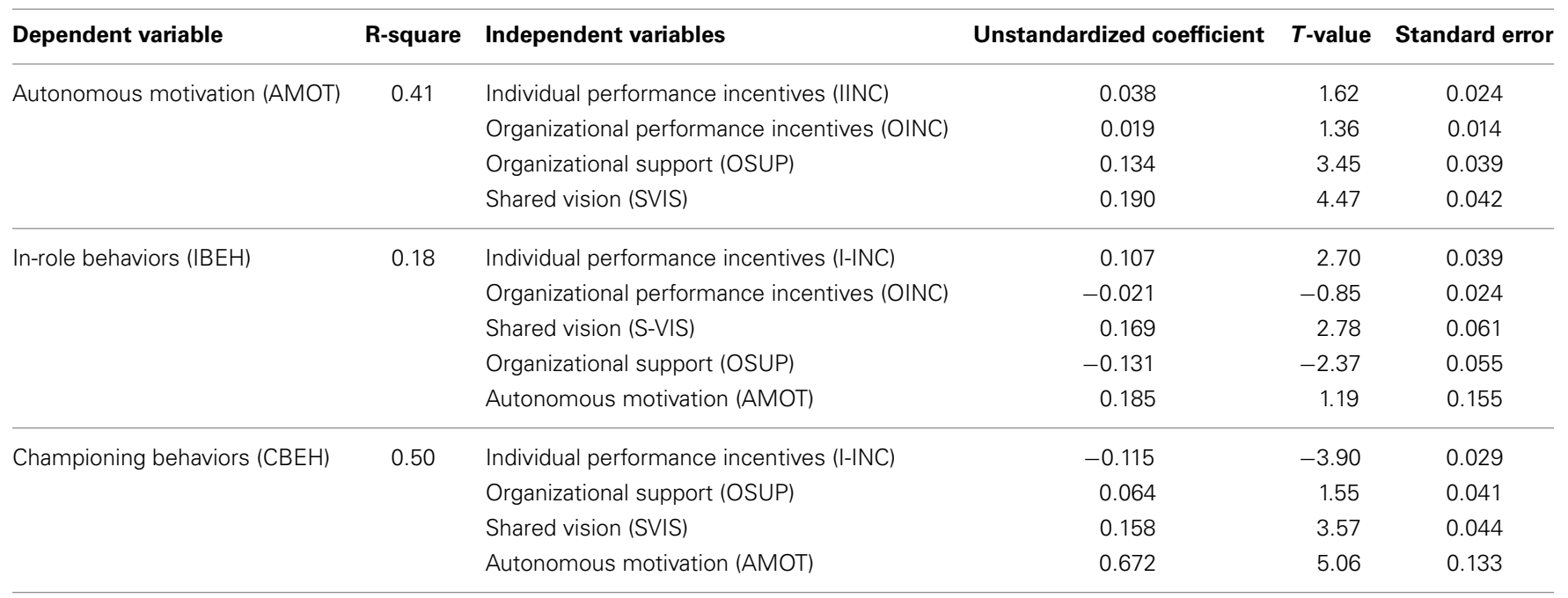

To evaluate discriminant validity, AVE for each construct must be $>0.50$ and exceed the values of MSV and ASV (Fornell and Larcker, 1981). Again, all constructs exceed desired thresholds except for Championing Behaviors. Because its AVE is greater than its MSV or ASV and based on the strengths of other statistics, the Championing Behaviors construct was considered to have acceptable discriminant validity.

The hypothesized structural model was developed and evaluated in AMOS. It should be noted that all structural model statistics were calculated after inclusion of the control variables acquisition age (AAGE), participant tenure (PTEN, and participant gender PGEN). Table 5 contains the resulting goodness of fit statistics. The initial model approached good fit, however, the modification indices suggested that the addition of three regression paths would improve model fit. Paths from Individual Performance Incentives to Championing Behaviors, Organizational Support to In-Role Behaviors, and Shared Vision to In-Role Behaviors were added to the model and analyzed. While the fit did not improve much, all added paths were statistically significant and therefore, were retained in the final structural model. The respecified model and impact of these nonhypothesized paths will be discussed at length in the Findings and Discussion sections.

Table 6 lists the statistical relationships between the constructs in the final structural model. The $r^{2}$ statistic represents the amount of variability in the dependent variable that can be explained by the independent variables. The unstandardized coefficient indicates raw strength of the influence of each independent variable on the dependent variable. Finally, the $t$-value provides the significance of each coefficient. A graphical representation of the structural model summarizing the statistical relationships between constructs is shown in Figure 3.

The researchers evaluated the mediating effects of Autonomous Motivation using techniques developed by Mathieu and Taylor (2006). These techniques constrain each path in a mediated relationship in an iterative process to determine their significance using methods such as the Sobel test and bootstrapping (Mathieu and Taylor, 2006). Mathieu and Taylor
Table 7 | Mediation effects.

\begin{tabular}{ll}
\hline Hypothesized mediated paths & $\begin{array}{l}\text { Mediation effect of autonomous } \\
\text { motivation (A-MOT) }\end{array}$
\end{tabular}

Individual incentives (I-INC) $\Rightarrow$ In-role No mediation; direct effect

behaviors (I-BEH)

Individual incentives (I-INC) $\Rightarrow \quad$ Partial mediation

Championing behaviors (C-BEH)

Organizational incentives (O-INC) $\Rightarrow \quad$ No mediation

In-role behaviors (I-BEH)

Organizational incentives (O-INC) $\Rightarrow \quad$ No mediation

Championing behaviors (C-BEH)

Organizational support (O-SUP) $\Rightarrow \quad$ No mediation; direct effect

In-role behaviors (I-BEH)

Organizational support (O-SUP) $\Rightarrow \quad$ Indirect effects mediation

Championing behaviors (C-BEH)

Shared vision $(\mathrm{S}-\mathrm{VIS}) \Rightarrow$ In-role $\quad$ No mediation

behaviors (I-BEH)

Shared vision (S-VIS) $\Rightarrow$ Championing Partial mediation

behaviors (C-BEH)

(2006) assert that these techniques will identify indirect effects that other methods will reject. Indirect effects describe variables that mediate the relationship between independent and dependent variables that are not significantly correlated to each other. In other words, the absence of significant total effect between independent and dependent variables often cause researchers to mistakenly reject significant mediated relationships. Table 7 lists a summary of the results of mediation testing.

A multigroup analysis (Jöreskog, 1971; Byrne, 2001) assessed the moderating effects of senior vs. middle managers and managers under 45 years old vs. those over 45 . The analysis for each group was conducted in three steps. First, the factor loadings of the AMOS measurement model were constrained equal and compared to the unconstrained model. A significant difference between each model's chi-square at a $90 \%$ confidence interval served as the threshold to reject the null hypothesis that 
Table 8 | Results of multigroup analysis for managers over and under 45 years old.

\begin{tabular}{|c|c|c|c|c|}
\hline \multirow[t]{2}{*}{ Construct paths } & \multicolumn{2}{|c|}{ Under 45} & \multicolumn{2}{|c|}{45 and over } \\
\hline & Coefficient & $T$-value & Coefficient & $T$-value \\
\hline Individual incentives (IINC) $\Rightarrow$ In-role behaviors (IBEH) & 0.132 & 2.078 & 0.114 & 1.058 \\
\hline Individual incentives (IINC) $\Rightarrow$ Championing behaviors (CBEH) & -0.278 & -4.278 & -0.185 & -2.006 \\
\hline Individual incentives (IINC) $\Rightarrow$ Autonomous motivation (AMOT) & 0.020 & 0.501 & 0.173 & 2.846 \\
\hline Organizational incentives (O-INC) $\Rightarrow$ In-role behaviors (I-BEH) & -0.179 & -2.627 & -0.033 & -0.298 \\
\hline Organizational support (O-SUP) $\Rightarrow$ Championing behaviors (C-BEH) & 0.259 & 3.575 & 0.137 & 1.285 \\
\hline Organizational support (O-SUP) $\Rightarrow$ Autonomous motivation (AMOT) & 0.125 & 2.887 & 0.233 & 3.177 \\
\hline Shared vision (S-VIS) $\Rightarrow$ In-role behaviors (I-BEH) & 0.146 & 1.931 & 0.388 & 2.975 \\
\hline Shared vision (S-VIS) $\Rightarrow$ Championing behaviors (C-BEH) & 0.283 & 3.465 & 0.254 & 2.633 \\
\hline Shared vision (S-VIS) $\Rightarrow$ Autonomous motivation (AMOT) & 0.262 & 5.307 & 0.226 & 2.965 \\
\hline
\end{tabular}

Coefficients listed are unstandardized regression weights.

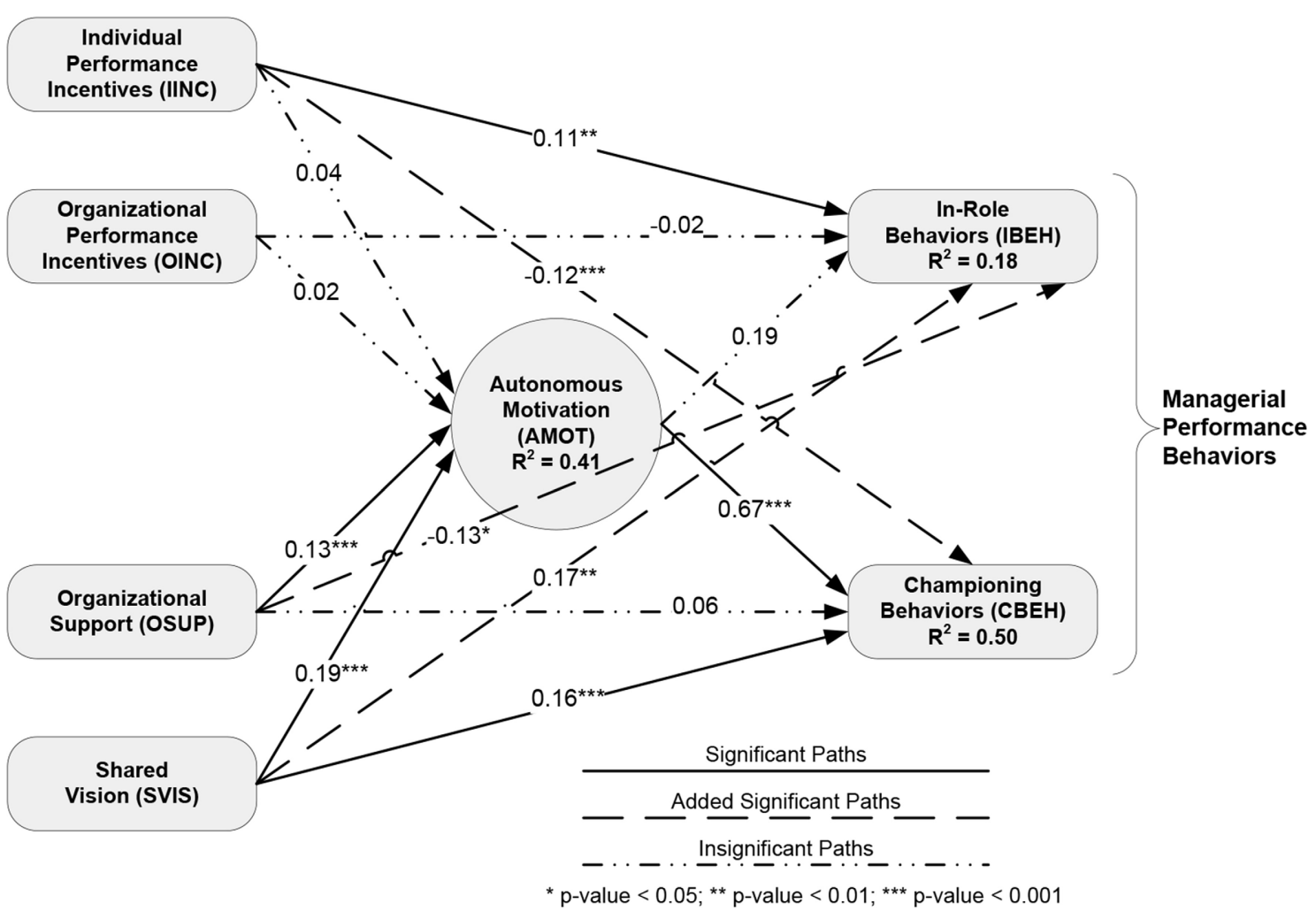

FIGURE 3 | Path diagram.

the measurement model was invariant across groups. Because the measurement model was not invariant across management level or age groups, each constraint was released and compared via subsequent models to determine which specific factors were non-invariant. Finally, the non-invariant factors were allowed to estimate freely, which raised the chi-square significance to 0.183 for senior vs. middle managers and 0.083 for managers under vs. over 45 years old.

A similar procedure was used to assess structural model invariance. The causal paths between constructs were constrained equal and compared across groups. Interestingly, all paths were invariant across management level groups while none of the paths were 
Table 9 | Summary of hypothesis testing.

\section{Hypothesis}

Hypothesis 1: Individual performance incentives positively influence in-role behaviors after controlling for autonomous motivation

Hypothesis 2: Organizational performance incentives positively influence in-role behaviors after controlling for autonomous motivation

Hypothesis 3: Individual performance incentives have a stronger (more positive) influence on in-role behaviors than organizational

Supported

performance incentives

Hypothesis 4: Individual performance incentives negatively influence autonomous motivation

Rejected

Hypothesis 5: Organizational performance incentives negatively influence autonomous motivation.

Rejected

Hypothesis 6: Autonomous motivation positively influences in-role behaviors.

Hypothesis 7: Autonomous motivation positively influences championing behaviors

Hypothesis 8: Autonomous motivation has a stronger (more positive) influence on championing behaviors than in-role behaviors

Hypothesis 9: Autonomous motivation negatively mediates the influence of individual performance incentives on in-role behaviors

Hypothesis 10: Autonomous motivation negatively mediates the influence of organizational performance incentives on in-role behaviors

Hypothesis 11: Autonomous motivation negatively mediates the influence of individual performance incentives on championing behaviors

Hypothesis 12: Autonomous motivation negatively mediates the influence of organizational performance incentives on championing

behaviors

Hypothesis 13: Organizational support positively influences autonomous motivation

Rejected

Supported

Supported

Rejected

Rejected

Rejected

Rejected

Hypothesis 14: Organizational support positively influences championing behaviors

Supported

Hypothesis 15: Autonomous motivation positively mediates the influence of organizational support on in-role behaviors

Hypothesis 16: Autonomous motivation positively mediates the influence of organizational support on championing behaviors

Rejected

Rejected

Hypothesis 17: Share vision positively influences autonomous motivation

Hypothesis 18: Share vision positively influences championing behaviors

Hypothesis 19: Autonomous motivation positively mediates the influence of shared vision on in-role behaviors

Hypothesis 20: Autonomous motivation positively mediates the influence of shared vision on championing behaviors

Table 10 | Construct paths w/opposite significance and regression differences $>0.02$.

\begin{tabular}{|c|c|c|c|c|}
\hline Construct paths & \multicolumn{2}{|c|}{ Under 45} & \multicolumn{2}{|c|}{45 and over } \\
\hline Autonomous motivation (AMOT) $\Rightarrow$ Championing behaviors $(\mathrm{C}-\mathrm{BEH})$ & 0.346 & 2.486 & 0.151 & 0.494 \\
\hline Organizational incentives (O-INC) $\Rightarrow$ In-role behaviors (I-BEH) & -0.179 & -2.627 & -0.033 & -0.298 \\
\hline Shared vision (S-VIS) $\Rightarrow$ In-role behaviors (I-BEH) & 0.146 & 1.931 & 0.388 & 2.975 \\
\hline
\end{tabular}

Coefficients listed are unstandardized regression weights.

invariant across the manager age groups. Releasing each of the constraints across age groups revealed specific differences of how our hypothesized model applied to managers over and under 45 years old. Table 8 provides information useful in deciphering and discussing these differences in the next sections.

The structural model also controlled for acquisition age, manager tenure and manager gender. Of nine possible effects (nine paths connecting three controls to two dependent and one mediating variables), only two were significant. Managers' tenure was likely to positively influence their in-role behaviors (unstandardized regression coefficient $=0.155 ; t$-value 2.77) and acquisition age was likely to positively influence managers' autonomous motivation (unstandardized regression coefficient $=$ $0.125 ;$-value 2.26 ).

\section{DISCUSSION}

Results of the hypotheses tested are shown in Table 9. For a listing of $r^{2}$ values, regression coefficients and $t$-values please refer to Table 6 and Figure 3.

\section{INFLUENCES ON CHAMPIONING BEHAVIORS}

The combination of performance incentives, organizational support, shared vision and autonomous motivation accounted for $50 \%$ of the variance in championing behaviors. Shared vision had a direct, positive and highly likely influence on championing behaviors. In fact, it was the only independent variable to have a direct positive impact on championing behaviors.

Shared vision also indirectly influenced championing behaviors via autonomous motivation, indicating partial mediation. The total effect of shared vision on championing behaviors was 0.286 . Comparing the total effects of the independent variables, shared vision had a stronger impact on championing behaviors than individual incentives, organizational incentives and organizational support combined.

An unexpected finding indicated that individual performance incentives directly reduced championing behaviors. At first glance, this was counterintuitive because individual incentives target in-role behaviors only. However, researchers have proposed an inverse relationship between in-role and organizational 
citizenship behaviors (OCBs). Bergeron (2007) proposed that under an outcome based reward system, increases in OCBs will result in decreases in in-role behaviors and vice-versa. Given the fact that OCBs and championing behaviors are both forms of extra-role behaviors (Morrison and Phelps, 1999), it appears that our findings reflect Bergeron's work.

The mediation analysis reported a significant and positive indirect mediation between organizational support and championing behaviors via autonomous motivation. In this case, the indirect mediation at nearly $50 \%$ stronger than the nonsignificant direct effect, 0.09 vs. 0.06 , respectively.

The mediation analysis also showed that autonomous motivation partially mediated the influence of individual incentives on championing behaviors. This finding conflicted with the unconstrained analysis in Figure 3 depicting the path between individual incentives and autonomous motivation as non-significant (negating mediation). As such, the mediation analysis provided the more accurate assessment of the mediation relationship by isolating individual paths to better examine their effects and by using bias-corrected bootstrapping for estimation.

The resulting finding indicated that autonomous motivation positively mediated the influence of individual incentives on championing behaviors. However, the unexpected negative direct effect between individual incentives and championing behaviors resulted in a negative total effect. It should also be noted that the positive indirect effect of individual incentives on championing behaviors was very weak. The regression coefficient of 0.03 was only $25 \%$ of the direct effect.

Finally, organizational support did not positively influence championing behaviors. In addition to a low $t$-value of 1.55 , organizational support had a weak influence on championing behaviors with a regression coefficient of 0.06 .

\section{INFLUENCES ON IN-ROLE BEHAVIORS}

The combination of performance incentives, organizational support, shared vision and autonomous motivation accounted for only $18 \%$ of the variance in in-role behaviors. Of the three hypothesized direct effects, only one, individual incentives had a significant effect. Neither organizational incentives nor autonomous motivation significantly influenced in-role behaviors. Because autonomous motivation did not significantly influence in-role behaviors, none of the mediation hypotheses for in-role behaviors were significant. However, we caution the confidence in this finding because of the high standard error of 0.155 for the autonomous motivation (AMOT) $\rightarrow$ in-role behaviors (IBEH) path which certainly increases the chance for a Type 1 error. A lower standard error would negate the rejection of several of the mediation hypotheses, substantially changing the findings of the overall study. In consideration of subsequent research, researcher should improve the items measuring autonomous motivation to achieve more accurate predictions of mediation hypotheses.

The most interesting finding here was how little organizational incentives influenced in-role behaviors. With a direct effect of -0.021 , indirect effect of 0.004 and total effect of -0.017 , all values were non-significant. This finding suggested that the common practice of providing substantial organizational incentives to M\&A managers is totally ineffective.

An unexpected finding revealed that shared vision directly and positively influenced in-role behaviors. In fact, the influence of shared vision on in-role behaviors was 35\% stronger than the influence of individual incentives on in-role behaviors with regression coefficients of 0.17 and 0.11 , respectively. This is quite intriguing considering the strong pay-performance link between individual incentives and in-role behaviors asserted in compensation literature (Bucklin and Dickinson, 2001; McGee et al., 2006). We believe this may be an engaging topic for further research.

The previous section discussed the opposite effects that individual incentives had on in-role and championing behaviors and how it supported the work of Bergeron (2007). In other words, these opposite effects mimicked the inverse relationship between in-role and OCBs proposed by Bergeron. A similar phenomenon was caused by the negative direct effect of organizational support on in-role behaviors vs. the positive indirect effect of organizational support on championing behaviors. As organizational support increased, championing behaviors increased and in-role behaviors decreased.

\section{INFLUENCES ON AUTONOMOUS MOTIVATION}

The combination of performance incentives, organizational support, and shared vision accounted for $41 \%$ of the variance in autonomous motivation. Organizational support and shared vision were the major predictors of autonomous motivation virtually contributing all of the effect. Conversely, the regression coefficients linking individual and organizational incentives to autonomous motivation were among the weakest in the study at 0.04 and 0.02 , respectively. This is an interesting outcome considering SDT posits that incentives decrease autonomous motivation. In this study and setting, SDT did not hold. In fact, the effects of performance incentives on autonomous motivation paled in comparison to the effects of organizational support and shared vision on autonomous motivation.

\section{COMPARATIVE HYPOTHESES}

Hypotheses 3 and 8 predicted the comparative strengths of two pairs of conceptualized paths. Hypothesis 3 asserted that the stronger pay-performance link between individual incentives and in-role behaviors would result in a stronger influence than organizational incentives. The influence of individual incentives was not only substantially stronger but was significant as compared to a weak and non-significant effect for organizational incentives.

Hypothesis 8 posited that autonomous motivation would be a stronger predictor of championing behaviors than in-role behaviors. The data supported this hypothesis. The regression coefficient for its effect on championing behaviors was 3.5 times stronger than its effect on in-role behaviors. In addition, the data suggested much more confidence in the ability of autonomous motivation to predict championing behaviors with a $t$-value of 5.06 compared to 1.19 .

\section{CONTROLS}

The multigroup SEM analysis indicated that the structural model was invariant across senior and middle managers but not 
invariant across managers over and under 45 years old. Table 8 lists the regression coefficients and $t$-values for each path of the diagram depicted in Figure 3 for managers over and under 45 years old.

Referring to Table 8, there are 13 paths that AMOS reported as significantly different for managers under vs. over 45 years old. Of the 13 paths, 8 of them disagreed on significance, that is, one path was significant and the other was not significant. Of those 8 paths, 6 of them have regression coefficients with differences $>0.02$. These 6 paths represent the major differences in construct relationships between managers under 45 and those over 45 and are listed in Table 10.

Per Table 10, the championing behaviors of managers under 45 were more sensitive to organizational support and autonomous motivation than those over 45 . The regression coefficients for younger managers were roughly twice the strength of these effects on older managers. The in-role behaviors of younger managers were also more sensitive to organizational incentives and autonomous motivation, reporting regression coefficients between 3.8 and 5.4 times those for older managers. These findings indicated that younger managers cared more about how the organization perceives them. The behaviors of younger managers were also more influenced by how much they internalized the organization's goals (autonomous motivation). In general, the data indicated that younger managers were much more sensitive to the support, incentives and goals of the organization than older managers.

Conversely, older managers cared more about shared vision, defined in this study as their alignment with the overall direction and purpose of the organization. Shared vision positively influenced the in-role behaviors of older managers more than 2.5 times that of younger managers. As individuals age, they are less likely to look for a new job (Martin, 1979; Griffeth et al., 2000). In mergers and acquisitions, individuals who identify with the vision of the organization are also less likely to look for a new job and more likely to increase their performance (Haslam, 2001; Cartwright, 2005). These two notions suggest that older M\&A employees should be more sensitive to shared vision and that increases in shared vision should reduce turnover intent and increase performance.

The multigroup analysis also indicated that individual incentives influenced the autonomous motivation of older managers much more than younger managers. However, because autonomous motivation did not significantly influence either inrole or championing behaviors of older managers, this finding doesn't matter. Regardless of how much individual incentives impact the autonomous motivation of older managers, it does not significantly influence their behaviors.

The structural model controlled for acquisition age, manager tenure and manager gender. Of the nine possible effects, only two effects were significant. First, the findings reported a positive relationship between manager tenure and in-role behaviors with a regression coefficient of 0.16 and $t$-value of 2.77 . This outcome seems intuitive as one would expect managers to become more efficient in their formal, in-role behaviors over time.

The findings also reported a significant positive relationship between acquisition age and autonomous motivation with a regression coefficient of 0.13 and a $t$-value of 2.26. These effects were consistent with researchers who posit that it takes time for employees to reconcile their feelings of uncertainty regarding large-scale organizational change (Liu and Perrewé, 2005), resulting in a temporary reduction in work motivation, specifically in mergers and acquisitions (Seo and Hill, 2005).

\section{M\&A PRACTICE IS WRONG ON CHAMPIONING BEHAVIORS}

The findings directly conflict with one of the most common and longstanding M\&A assumptions that organizational performance incentives induce discretionary behaviors from acquired managers (Kaplan, 2000; Hitt et al., 2001; Larsson and Finkelstein, 2002). According to the data, organizational incentives did not significantly affect championing behaviors directly or indirectly. In fact, AMOS reported the total effect of organizational incentives on championing behaviors at a negligible 0.01 .

These findings suggest that the ubiquitous use of stock options and profit sharing plans in M\&A may be a waste of time and money. Seemingly, the implication to practice would be to eliminate organizational performance incentives. However, the practice of offering acquired manager's stock options and profit sharing has become an expected practice. These expectations may contribute to the loss of incentive power, possibly explaining the poor effects of these incentives on manager behaviors. In either case, should an acquirer fail to offer organizational incentives or offer substantially reduced versions, the effect on management morale and turnover could be devastating to the company. This dilemma suggests an agenda for future research, exploring the effects of various levels of organizational performance incentives on managerial morale, turnover and performance in an M\&A context.

\section{M\&A PRACTICE IS WRONG ON SHARED VISION}

Shared vision was the only independent variable that positively influenced both championing and in-role behaviors. Surprisingly, shared vision impacted in-role behaviors more than individual performance incentives, despite its strong pay-performance link. Shared vision was also one of only two variables to significantly influence autonomous motivation.

One of the first duties of acquirers is to establish performance incentives of their newly acquired managers. In fact, stock incentives for CEOs and senior managers are usually established prior to the official transaction as part of the legal paperwork Details of profit sharing plans and individual performance bonuses soon follow.

The study findings imply that M\&A practitioners should establish a higher priority on shared vision. Other researchers have identified shared vision as essential to the successful performance of merged and acquired organizations (Haspeslagh and Jemison, 1991; Sitkin and Pablo, 2005). Serial acquirers such as GlaxoSmithKline and Cisco Systems promote shared vision as an important part of their acquisition successes (DiGeorgio, 2001; Stahl and Mendenhall, 2005). Whereas, these sources base their arguments on qualitative findings, the present study contributes quantitative evidence to support the importance of shared vision, directly comparing their effects to those of performance incentives in an M\&A context. Furthermore, the strength 
of the quantitative results suggests that M\&A practitioners should prioritize shared vision above performance incentives.

\section{INDIVIDUAL INCENTIVES AND PRGANIZATIONAL SUPPORT}

Study findings indicated that individual incentives positively influenced in-role behaviors and negatively influenced championing behaviors. The absolute strengths of these bipolar effects were almost identical with direct effects of 0.11 and -0.12 , respectively. This finding was consistent with the assertions of some practitioners and researchers that individual incentives can work "too well," causing individuals to focus almost exclusively on inrole behaviors to the detriment of extra-role behaviors (Kohn and Thompson, 1993; Wright et al., 1993; Deckop et al., 1999; Hall and Murphy, 2003). Acquirers commonly address this issue by providing organizational incentives in addition to individual incentives to induce extra-role behaviors that foster cooperation and teamwork (FitzRoy and Kraft, 1995). Our findings supported the idea that individual incentives decrease championing behaviors but did not support the idea that introducing organizational incentives would offset the decrease.

The data did support the idea that increasing organizational support would offset the negative effects of individual incentives on championing behaviors. Organizational support positively influenced championing behaviors (indirect effect 0.09 ) but also negatively influenced in-role behaviors (direct effect -0.13). This supports the work of researchers who argue that focus on extra-role behaviors reduce the performance of in-role behaviors (Bergeron, 2007).

By highlighting the gains and costs of increasing individual incentives and organizational support, the study findings provide insights for cultivating desired managerial behaviors. For example, increasing organizational support for managers charged with large-scale change efforts should help foster the championing behaviors required to overcome resistance to aggressive growth and change. Conversely, increasing individual performance incentives should help cultivate the in-role behaviors of managers charged with sustaining day-to-day operational efficiencies, especially during periods of environmental disruptions typical in M\&As.

\section{AGE MATTERS}

The effect of organizational support on younger managers' championing behaviors was roughly 2 times stronger than older managers. The effect of organizational incentives on younger managers' in-role behaviors were over five times stronger than older managers. The degree that younger managers internalized current organizational goals (autonomous motivation) affected their championing and in-role behaviors 2-3.5 times more than older managers. In contrast, shared vision influenced the inrole behaviors of older managers 2.5 times more than younger managers.

These findings imply a difference in temporal focus for younger vs. older managers. The items of concern for younger managers, organizational support, incentives and current goals represent current actions, promises or objectives. The concern for older managers, shared vision, focuses more on what the company will become in the future. While plausible, there is little evidence in the scope of the present study to support this explanation. However, this may be an interesting topic for future research.

As mentioned earlier, the effect of organizational incentives on younger managers' in-role behaviors were over five times stronger than older managers. This statistic implies that older managers performed their formal duties more consistently than younger managers, despite fluctuations in organizational incentives. This implication was supported by the substantially lower standard deviation for in-role behaviors of older vs. younger managers at 0.62 vs. 0.77 . In addition, the mean for in-role behaviors of older managers (3.85) was higher than younger managers (3.72), inferring that older managers performed their formal duties better than younger managers as well as more consistently. The data suggests that acquirers should note the ages of their managers when designing organizational incentive plans.

\section{LIMITATIONS}

The researchers acknowledge several limitations of this study. First, the study is cross-sectional which means the causal relationships can only be hypothesized from previous research and theory. Future research should utilize a longitudinal approach as a more rigorous analysis of our proposed causal relationships.

Second, common method variance was present due to the nature of the self-report data. Therefore, we modeled a latent common method factor that was constrained to load equally on all observed variables in the measurement and structural models. By doing so, we attempted to partial out the variance due to the common method.

Finally, the sample included M\&As owned by private equity firms only. This is but one segment of many in the M\&A domain. Replication of the study exploring other segments would be required to test the generalizability of our findings.

\section{CONCLUSION}

To our knowledge, this is the first M\&A study to integrate financial and psychological drivers of managerial performance into a single testable model. Although this initial study certainly requires further testing and refinement, we assert that the findings provide valuable insights toward understanding the drivers of managerial behaviors within mergers and acquisitions. Specifically, the study provides evidence that shared vision is far more effective at driving managerial performance, as defined by in-role and championing behaviors, than common M\&A practices of providing financial incentives. This is an important step forward in reducing the dismal failure rates that continue to plague the M\&A domain.

\section{REFERENCES}

Adams, J. S. (1965). Inequity in social exchange. Adv. Exp. Psychol. 2, 267-299. doi: 10.1016/S0065-2601(08)60108-2

Akrivou, K., Boyatzis, R. E., and McLeod, P. L. (2006). The evolving group: towards a prescriptive theory of intentional group development. J. Manag. Dev. 25, 689-706. doi: 10.1108/02621710610678490

Ashforth, B. E., and Humphrey, R. H. (1995). Emotion in the workplace: a reappraisal. Hum. Relat. 48, 97. doi: 10.1177/001872679504800201

Barksdale, K., and Werner, J. M. (2001). Managerial ratings of in-role behaviors, organizational citizenship behaviors, and overall performance: testing different models of their relationship. J. Bus. Res. 51, 145-155. doi: 10.1016/S01482963(99)00061-2 
Bentler, P. M., and Bonett, D. G. (1980). Significance tests and goodness of fit in the analysis of covariance structures. Psychol. Bull. 88, 588-606. doi: 10.1037/00332909.88.3.588

Bergeron, D. M. (2007). The potential paradox of organizational citizenship behavior: good citizens at what cost? Acad. Manag. Rev. 32, 1078-1095. doi 10.5465/AMR.2007.26585791

Bertoncelj, A., and Kovač, D. (2007). An integrated approach for a higher success rate in mergers and acquisitions. Zbornik radova Ekonomskog fakulteta u Rijeci: casopis za ekonomsku teoriju i praksu 25, 167-188.

Black, A. E., and Deci, E. L. (2000). The effects of instructors' autonomy support and students' autonomous motivation on learning organic chemistry: a selfdetermination theory perspective. Sci. Educ. 84, 740-756. doi: 10.1002/1098237X(200011)84:6<740::AID-SCE4>3.0.CO;2-3

Blau, P. M. (1964). Exchange and Power in Social Life. New York, NY: Wiley, 56-58.

Booth, A. L., and Frank, J. (1999). Earnings, productivity, and performance-related pay. J. Labor Econ. 17, 447-463. doi: 10.1086/209927

Boyatzis, R. E. (2006). An overview of intentional change from a complexity perspective. J. Manag. Dev. 25, 607-623. doi: 10.1108/02621710610678445

Boyatzis, R. E. (2008). PNEA Survey. Cleveland, OH: Case Western Reserve University.

Boyatzis, R. E., and McKee, A. (2005). Resonant Leadership. Boston, MA: Harvard Business School Press.

Bruner, R. F. (2002). Does M\&A pay? A survey of evidence for the decision-maker J. Appl. Finance 12, 48-68. doi: 10.1111/j.1745-6622.2004.00007.x

Bucklin, B. R., and Dickinson, A. M. (2001). Individual monetary incentives: a review of different types of arrangements between performance and pay. J. Organ. Behav. Manag. 21:3. doi: 10.1300/J075v21n03_03

Byrne, B. M. (2001). Structural Equation Modeling with AMOS: Basic Concepts, Applications, and Programming. London: Lawrence Erlbaum.

Cartwright, S. (2005). Mergers and acquisitions: an update and appraisal. Int. R. Ind. Organ. Psychol. 20, 1-38. doi: 10.1002/0470029307

Cartwright, S., and Cooper, C. L. (1996). Managing Mergers, Acquisitions and Strategic Alliances: Integrating People and Culture. New York, NY: Butterworth Heinemann.

Cartwright, S., and Schoenberg, R. (2006). Thirty years of mergers and acquisitions research: recent advances and future opportunities. Br. J. Manag. 17, S1-S5. doi: 10.1111/j.1467-8551.2006.00475.x

Chen, Z., Eisenberger, R., Johnson, K. M., Sucharskid, I. L., and Aselagee, J. (2009). Perceived organizational support and extra-role performance: which leads to which? J. Soc. Psychol. 149, 119. doi: 10.3200/SOCP.149.1.119-124

Chiaburu, D. S., and Baker, V. L. (2006). Extra-role behaviors challenging the status-quo. J. Manag. Psychol. 21, 620-637. doi: 10.1108/02683940610690178

Coffey, J., Garrow, V., and Holbeche, L. (2003). Reaping the Benefits of Mergers and Acquisitions: In Search of the Golden Fleece. New York, NY: ButterwotrhHeinemann.

Cropanzano, R., Bowen, D. E., and Gilliland, S. W. (2007). The management of organizational justice. Acad. Manag. Perspect. 21, 34-48. doi: 10.5465/AMP.2007.27895338

Cullinan, G., Le Roux, J. M., and Weddigen, R. M. (2004). When to walk away from a deal. Harv. Bus. Rev. 82, 96-104.

Deci, E. L., and Ryan, R. M. (1985). Intrinsic Motivation and Self-Determination in Human Behavior. New York, NY: Springer.

Deci, E. L., and Ryan, R. M. (1987). The support of autonomy and the control of behavior. J. Pers. Soc. Psychol. 53, 1024-1037. doi: 10.1037/0022-3514.53.6.1024

Deci, E. L., and Ryan, R. M. (2000). The "What" and "Why" of goal pursuits: human needs and the self-determination of behavior. Psychol. Inq. 11, 227-268. doi 10.1207/S15327965PLI1104_01

Deci, E. L., and Ryan, R. M. (2008). Self-Determination Theory: An Approach to Human Motivation and Personality. University of Rochester. Available online at: http://www.psych.rochester.edu/SDT/index.html (Accessed October 29, 2008).

Deckop, J. R., Mangel, R., and Cirka, C. C. (1999). Getting more than you pay for: organizational citizenship behavior and pay-for-performance plans. Acad. Manag. J. 42, 420-428. doi: 10.2307/257012

Devos, G., Vanderheyden, K., and Van Den Broeck, H. (2001). "A framework for assessing commitment to change: Process and context variables of organizational change," in Annual Meeting of the Academyof Management (Washington, DC).

DiGeorgio, R. M. (2001). Making mergers and acquisitions work: what we know and don't know-Part I. J. Change Manag. 3, 134-148. doi: 10.1080/714042529
Douma, M. U., Bilderbeek, J., Idenburg, P. J., and Looise, J. K. (2000). Strategic alliances managing the dynamics of fit. Long Range Plann. 33, 579-598. doi: 10.1016/S0024-6301(00)00062-5

Dvir, T., Kass, N., and Shamir, B. (2004). The emotional bond: vision and organizational commitment among high-tech employees. J. Org. Change Manag. 17, 126-143. doi: 10.1108/09534810410530575

Edmonson, A. (1999). Psychological safety and learning behavior in work teams. Adm. Sci. Q. 44, 350-353. doi: 10.2307/2666999

Eisenberger, R., Fasolo, P., and Davis-LaMastro, V. (1990). Perceived organizational support and employee diligence, commitment, and innovation. J. Appl. Psychol. 75, 51-59. doi: 10.1037/0021-9010.75.1.51

Eisenberger, R., Huntington, R., Hutchison, S., and Sowa, D. (1986). Perceived organizational support. J. Appl. Psychol. 71, 500-507. doi: 10.1037/00219010.71.3.500

Fields, D. L. (2002). Taking the Measure of Work: A Guide to Validated Scales for Organizational Research and Diagnosis. London: Sage Publications.

FitzRoy, F. R., and Kraft, K. (1995). On the choice of incentives in firms. J. Econ. Behav Org. 26, 145-160. doi: 10.1016/0167-2681(94)00066-N

Flanigan, J. (2005). Billions Pour into Private Equity. Los Angeles, CA: Los Angeles Times.

Fornell, C., and Larcker, D. F. (1981). Evaluating structural equation models with unobservable variables and measurement models. J. Mark. Res. 18, 39-50. doi: $10.2307 / 3151312$

Frey, B. S., and Jegen, R. (2001). Motivation crowding theory. J. Econ. Surv. 15, 589-611. doi: 10.1111/1467-6419.00150

Frey, B. S., and Oberholzer-Gee, F. (1997). The cost of price incentives: an empirical analysis of motivation crowding- out. Am. Econ. Rev. 87, 746-755.

Frey, B. S., and Osterloh, M. (2005). "Yes, managers should be paid like bureaucrats," in CESIFO Working Paper No. 1379 Category 2: Public Choice (Zürich).

Friedrich, T. L., Byrne, C. L., and Mumford, M. D. (2009). Methodological and theoretical considerations in survey research. Leadersh. Q. 20, 57-60. doi: 10.1016/j.leaqua.2009.01.001

Gaertner, S. L., Bachman, B. A., Dovidio, J., and Banker, B. S. (2001). Corporate mergers and stepfamily marriages: identity, harmony, and commitment Soc. Identity Process. Org. Contexts 13, 265-282. doi: 10.1177/108886830 8326751

Gagné, M., Boies, K., Koestner, R., and Martens, M. (2004). How Work Motivation is Related to Organizational Commitment: A Series of Organizational Studies. Portland, OR: Concordia University.

Gagné, M., Chemolli, E. F., Forest, J., and Koestner, R. (2009). A Temporal Analysis of the Relation Between Organizational Commitment and Work Motivation. Portland, OR: Concordia University.

Gagne, M., and Deci, E. L. (2005). Self-determination theory and work motivation. J. Organ. Behav. 26, 331-362. doi: 10.1002/job.322

Gagne, M., and Forest, J. (2008). The study of compensation systems through the lens of self-determination theory: reconciling 35 years of debate. Can. Psychol. 49, 225-232. doi: 10.1037/a0012757

Gagné, M., and Koestner, R. (2002). "Self-determination theory as a framework for understanding organizational commitment," in Paper Presented at the Annual Meeting of the Society for Industrial and Organizational Psychology (Toronto, ON).

Gerhart, B. A., and Rynes, S. (2003). Compensation: Theory, Evidence, and Strategic Implications. Thousand Oaks, CA: Sage Publications.

Griffeth, R. W., Hom, P. W., and Gaertner, S. (2000). A meta-analysis of antecedents and correlates of employee turnover: update, moderator tests, and research implications for the next millennium. J. Manag. 26, 463. doi: $10.1177 / 014920630002600305$

Hair, J. F., Tatham, R. L., Anderson, R. E., and Black, W. (2006). Multivariate Data Analysis, 6th Edn. Englewood Cliffs, NJ: Prentice-Hall.

Hall, B. J., and Murphy, K. J. (2003). The trouble with stock options. J. Econ. Perspect. 17, 49-70. doi: 10.1257/089533003769204353

Haslam, S. (2001). A. Psychology in Organizations: The Social Identity Approach. London; Thousand Oaks: Sage.

Haspeslagh, P. C., and Jemison, D. B. (1991). Managing Acquisitions: Creating Value Through Corporate Renewal. New York, NY: The Free Press.

Hitt, M. A., Harrison, J. S., and Ireland, R. D. (2001). Mergers and Acquisitions: A Guide to Creating Value for Stakeholders. New York, NY: Oxford University Press.

Hogan, E. A., and Overmeyer-Day, L. (1994). The psychology of mergers and acquisitions. Int. Rev. Ind. Org. Psychol. 9, 247-247. 
Hu, L., and Bentler, P. M. (1999). Cutoff criteria for fit indexes in covariance structure analysis: conventional criteria versus new alternatives. Struct. Eq. Model. 6 1-55. doi: 10.1080/10705519909540118

James, H. S. (2005). Why did you do that? An economic examination of the effect of extrinsic compensation on intrinsic motivation and performance. J. Econ. Psychol. 26, 549-566. doi: 10.1016/j.joep.2004.11.002

Jöreskog, K. G. (1971). Simultaneous factor analysis in several populations. Psychometrika 36, 409-426. doi: 10.1007/BF02291366

Kaplan, S. N. (2000). Mergers and Productivity. Chiacgo: University Of Chicago, IL Press.

King, D. R., Dalton, D. R., Daily, C. M., and Covin, J. G. (2004). Meta-analyses of post-acquisition performance: indications of unidentified moderators. Strat. Manag. J. 25, 187-200. doi: 10.1002/smj.371

Kitching, J. (1974). Winning and losing with European acquisitions. Harv. Bus. Rev. $52,124-130$.

Kline, R. B. (1998). Principles and Practice of Structural Equation Modeling. New York, NY: Guilford Press.

Kline, R. B. (2005). Principles and Practice of Structural Equation Modeling. New York, NY: Guilford Publications.

Kohn, A., and Thompson, A. (1993). Why incentive plans cannot work. J. Appl. Psychol. 74, 54-63.

Larsson, R., and Finkelstein, S. (2002). Integrating strategic, organizational, and human resource perspectives on mergers and acquisitions. Merg. Acquis. Crit. Perspect. Bus. Manag. 10, 1-26. doi: 10.1287/orsc.10.1.1

Lazear Edward, P. (2000). Performance pay and productivity. Am. Econ. Rev. 90 , 1346-1361. doi: 10.1257/aer.90.5.1346

Lepper, M., and Greene, D. (1978). The Hidden Cost of Reward: New Perspectives on the Psychology of Human Motivation. New York, NY: Erlbaum.

Liu, Y., and Perrewé, P. L. (2005). Another look at the role of emotion in the organizational change: a process model. Hum. Res. Manag. Rev. 15, 263-280. doi: 10.1016/j.hrmr.2005.12.001

Malhotra, N. K., and Dash, S. (2011). Marketing Research an Applied Orientation (Paperback). London: Pearson Publishing.

Martin, T. N. Jr. (1979). A contextual model of employee turnover intentions. Acad. Manag. J. 22, 313-324. doi: 10.2307/255592

Masterson, S. S., and Stamper, C. L. (2003). Perceived organizational membership: an aggregate framework representing the employee-organization relationship. J. Organ. Behav. 24, 473-490. doi: 10.1002/job.203

Mathieu, J. E., and Taylor, S. R. (2006). Clarifying conditions and decision points for mediational type inferences in Organizational Behavior. J. Organ. Behav. 27, 1031. doi: $10.1002 /$ job.406

McGee, H. M., Dickinson, A. M., Huitema, B. E., and Culig, K. M. (2006). The effects of individual and group monetary incentives on high performance. Perform. Improv. Q. 19, 107. doi: 10.1111/j.1937-8327.2006.tb00387.x

Meyer, J. P., and Allen, N. J. (1991). A three-component conceptualization of organizational commitment. Hum. Res. Manag. Rev. 1, 61-89. doi: 10.1016/10534822(91) $90011-Z$

Meyer, J. P., Becker, T. E., and Vandenberghe, C. (2004). Employee commitment and motivation: a conceptual analysis and integrative model. J. Appl. Psychol. 89, 991-1007. doi: 10.1037/0021-9010.89.6.991

Meyer, J. P., and Herscovitch, L. (2001). Commitment in the workplace: toward a general model. Hum. Res. Manag. Rev. 11, 299-326. doi: 10.1016/S10534822(00)00053-X

Meyer, J. P., Stanley, D. J., Herscovitch, L., and Topolnytsky, L. (2002). Affective, continuance, and normative commitment to the organization: a meta-analysis of antecedents, correlates, and consequences. J. Vocat. Behav. 61, 20-52. doi: 10.1006/jvbe.2001.1842

Millette, V., and Gagné, M. (2008). Designing volunteers' tasks to maximize motivation, satisfaction and performance: the impact of job characteristics on volunteer engagement. Motiv. Emot. 32, 11-22. doi: 10.1007/s11031-007-9079-4

Mitleton-Kelly, E. (2004). "Co-evolutionary integration: a complexity perspective on mergers and acquisitions," in 20th EGOS Colloquium (Slovenia: Ljubljana University).

Moorman, R. H., Blakely, G. L., and Niehoff, B. P. (1998). Does perceived organizational support mediate the relationship between procedural justice and organizational citizenship behavior? Acad. Manag. J. 41, 351-357. doi: $10.2307 / 256913$

Morrison, E. W., and Phelps, C. C. (1999). Taking charge at work: extrarole efforts to initiate workplace change. Acad. Manag. J. 42, 403-419. doi: 10.2307/257011
Murphy, K. J., Ashenfelter, O., and Card, D. (1999). "Executive compensation," in Handbook of Labor Economics, Vol. 3, eds O. Ashenfelter and D. Card (Amsterdam, Elsevier), 2485-2563.

Nunnally, J. C., and Bernstein, I. H. (1994). Psychometric Theory. New York, NY: McGraw Hill.

O'Reilly, C. A. III., and Chatman, J. (1986). Organizational commitment and psychological attachment: the effects of compliance, identification, and internalization on prosocial behavior. J. Appl. Psychol. 71, 492-499. doi: 10.1037/0021-9010.71.3.492

Podsakoff, P. M., MacKenzie, S. B., Lee, J. Y., and Podsakoff, N. P. (2003). Common method biases in behavioral research: a critical review of the literature and recommended remedies. J. Appl. Psychol. 88, 879-903. doi: 10.1037/00219010.88.5.879

Reuters. (2008). Reuters.com. Available online at: http://www.reuters.com/article/ pressRelease/idUS108430+17-Dec-2007+BW20071217

Rhoades, L., and Eisenberger, R. (2002). Perceived organizational support: a review of the literature. J. Appl. Psychol. 87, 698-714. doi: 10.1037/0021-9010. 87.4.698

Riketta, M. (2002). Attitudinal organizational commitment and job performance: a meta-analysis. J. Organ. Behav. 23, 257-266. doi: 10.1002/job.141

Rostand, A. (1994). "Optimising managerial decisions during the acquisition integration process," in 14th Annual Strategic Management Society International Conference (Paris).

Ryan, R. M., and Connell, J. P. (1989). Perceived locus of causality and internalization: examining reasons for acting in two domains. J. Pers. Soc. Psychol. 57, 749-761. doi: 10.1037/0022-3514.57.5.749

Ryan, R. M., and Deci, E. L. (2000a). Self-determination theory and the facilitation of intrinsic motivation, social development, and well-being. Am. Psychol. 55, 68-78. doi: 10.1037/0003-066X.55.1.68

Schein, E. H. (1980). Organizational Psychology. Englewood Cliffs, NJ: PrenticeHall.

Schneider, B., Brief, A. P., and Guzzo, R. A. (1996). Creating a climate and culture for sustainable organizational change. Organ. Dyn. 24, 7-19. doi: 10.1016/S0090-2616(96)90010-8

Senge, P. M. (1990). The Fifth Discipline. New York, NY: Doubleday.

Seo, M. G., and Hill, N. S. (2005). Understanding the human side of merger and acquisition: an integrative framework. J. Appl. Behav. Sci. 41, 422. doi: $10.1177 / 0021886305281902$

Sheldon, K. M., Turban, D. B., Brown, K. G., Barrick, M. R., and Judge, T. A. (2003). Applying self-determination theory to organizational research Res. Pers. Hum. Resour. Manag. 22, 357-394. doi: 10.1016/S0742-7301(03) 22008-9

Sirower, M. L. (2000). The Synergy Trap: How Companies Lose the Acquisition Game. New York, NY: Free Press.

Sitkin, S., and Pablo, A. (2005). The Neglected Importance of Leadership in Mergers and Acquisitions. Mergers and Acquisitions: Managing Culture and Human Resources. Stanford, CA: Stanford Unviersity Press.

Stahl, G. K., and Mendenhall, M. E. (2005). Mergers and Acquisitions: Managing Culture and Human Resources. Stanford, CA: Stanford University Press.

Stahl, G. K., and Voigt, A. (2004). "Meta-analyses of the performance implications of cultural differences in mergers and acquisitions: integrating strategic, financial, and organizational perspectives," in Best Paper Proceedings-Annual Meeting of the Academy of Management (New Orleans, LA).

Sudarsanam, P. S. (2003). Creating Value from Mergers and Acquisitions: The Challenges: An Integrated and International Perspective. Englewood Cliffs, NJ: FT Prentice Hall.

Terry, D. J. (2003). "A social identity perspective on organizational mergers," in Social Identity at Work: Developing Theory for Organizational Practice, eds S. A Haslam, D. van Knippenberg, M. J. Platow, and N. Ellemers (New York, NY: Psychology Press Ltd.), 223-240.

Tichy, G. (2001). What do we know about success and failure of mergers? J. Ind Compet. Trade 1, 347-394. doi: 10.1023/A:1019521325295

Titmuss, R. M. (1971). The Gift Relationship: From Human Blood to Social Policy. New York, NY: Allen and Unwin.

Tsai, W., and Ghoshal, S. (1998). Social capital and value creation: the role of intrafirm networks. Acad. Manag. J. 41, 464-476. doi: 10.2307/257085

Tsui, A. S., Pearce, J. L., Porter, L. W., and Tripoli, A. M. (1997). Alternative approaches to the employee-organization relationship: does investment in employees pay off? Acad. Manag. J. 40, 1089-1121. doi: 10.2307/256928 
Turnley, W. H., Bolino, M. C., Lester, S. W., and Bloodgood, J. M. (2003). The impact of psychological contract fulfillment on the performance of in-role and organizational citizenship behaviors. J. Manag. 29, 187. doi: 10.1177/014920630302900204

Van-Oosten, E. B. (2006). Intentional change theory at the organizational level: a case study. J. Manag. Dev. 25, 707-717. doi: 10.1108/02621710610 678508

Wayne, S. J., Shore, L. M., and Liden, R. C. (1997). Perceived organizational support and leader-member exchange: a social exchange perspective. Acad. Manag. J. 40, 82-111. doi: 10.2307/257021

Wiersema, M. F., and Bantel, K. A. (1992). Top management team demography and corporate strategic change. Acad. Manag. J. 35, 91-121. doi: 10.2307/256474

Williams, G. C., and Deci, E. L. (1996). Internalization of biopsychosocial values by medical students: a test of self-determination theory. J. Pers. Soc. Psychol. 70, 767-779. doi: 10.1037/0022-3514.70.4.767

Williams, L. J., and Anderson, S. E. (1991). Job satisfaction and organizational commitment as predictors of organizational citizenship and in-role behaviors. J. Manag. 17, 601. doi: 10.1177/014920639101700305

Wright, P. M., George, J. M., Farnsworth, S. R., and McMahan, G. C. (1993). Productivity and extra-role behavior: the effects of goals and incentives on spontaneous helping. J. Appl. Psychol. 78, 374-381. doi: 10.1037/00219010.78.3.374

Conflict of Interest Statement: The author declares that the research was conducted in the absence of any commercial or financial relationships that could be construed as a potential conflict of interest.

Received: 20 September 2014; accepted: 29 November 2014; published online: 06 January 2015.

Citation: Clayton BC (2015) Shared vision and autonomous motivation vs. financial incentives driving success in corporate acquisitions. Front. Psychol. 5:1466. doi: 10.3389/fpsyg.2014.01466

This article was submitted to Personality and Social Psychology, a section of the journal Frontiers in Psychology.

Copyright (C) 2015 Clayton. This is an open-access article distributed under the terms of the Creative Commons Attribution License (CC BY). The use, distribution or reproduction in other forums is permitted, provided the original author(s) or licensor are credited and that the original publication in this journal is cited, in accordance with accepted academic practice. No use, distribution or reproduction is permitted which does not comply with these terms. 